Inv. Pesq. $\quad 23 \mid$ Págs. 169-230| junio 1963

\title{
Algunas regularidades en la distribución a escala pequeña y media de las poblaciones marinas de fitoplancton y en sus características funcionales
}

\author{
por \\ RAMON MARGALEF *
}

\section{INTRODUCCION}

En varias publicaciones recientes de tipo teórico (MARGALEF, 1961, 1962) se han discutido las relaciones entre estructura y función de los ecosistemas en su proyección espacial y temporal. Eistos trabajos se basaban en observaciones hechas en el mar y en cultivos de laboratorio, que en parte han sido publicadas y en parte permanecen inéditas ; pero que, en todo caso, no han sido discutidas con el suficiente detalle para que sirvan de base convincente a aquellas teorias que, por lo menos parcialmente, se pudieran considerar como extrapolaciones no totalmente justificadas. El presente artículo se destina a tender un puente, desde luego incompleto y provisional, entre los datos de observación y el citado edificio teórico.

También desea expresar cierto descontento con las formas acostumbradas de abordar los problemas que plantea la distribución del plancton en general y, más concretamente, del fitoplancton en una escala pequeña y media (de $10^{1}$ a $10^{5} \mathrm{~m}$ ). Este tema ha ocupado frecuentemente la atención de los planctólogos (véase Cassie, Cushing, Delia Croce, Krey y locs. cits.). Ningún planctólogo se da por satisfecho al averiguar que las distribuciones, que penosamente deduce de sus operaciones, son significativamente distintas de una hipotética distribución uniforme, porque hablar de distribución uniforme es hablar de lo inverosímil. Todos he-

* Instituto de Investigaciones Pesqueras. Paseo Nacional, s/n. Baroenona-3. Los presentes estudios han sido subvencionados, en parte, por el contrato NONR-3447(00) entre el Office of Naval Research, Department of the Navy, de Estados Unidos, y el Instituto de Investigaciones Pesqueras. 
mos tratado de poner en relación la distribución de determinada especie con la distribución de otras especies o con la de determinadas variantes ambientales que habían sido medidas simultáneamente. Pero los resultados que proporciona la aplicación de métodos estadísticos laboriosos (correlaciones múltiples, análisis factorial) son, a menudo, decepcionantes. Uno se pregunta si la ecología estará condenada a no salir de su atraso hasta que aprenda a comparar, en vez de valores referidos a un punto y a un instante (temperatura o concentración de células de determinada especie en un lugar determinado $y$ en un tiempo determinado), sus derivadas, es decir, gradientes y tendencias en el desarrollo de las poblaciones. Piénsese que la física no pudo avanzar hasta que sustituyó velocidades por aceleraciones. En el otro extremo, la caracterización de poblaciones mixtas con el nombre de asociaciones, biocenosis, etc., es muy imperfecta, subjetiva y va casi siempre asociada con la tendencia -no implícita en la creencia de poder definir comunidades- a trazar límites entre unas y otras comunidades, quebrantando la continuidad de las distribuciones reales.

Pero existe una base, probablemente sólida, sobre la que construir. De una parte, el caudal de datos de observación. De otra parte, el hecho que las distribuciones de cada especie en el espacio, con ser generalmęnte no uniformes, en su conjunto manifiestan cierto tipo de regularidad superior. Así como una mancha turbosa en la montaña se caracteriza por un complejo o mosaico de asociaciones que se disponen y ordenan según un motivo o apatterns característico, un torbellino ascendente en aguas marinas se caracterizará por una mancha central de un fitoplancton con unas pocas especies dominantes (serán, por ejemplo, Skeletonema costatum, Leptocylindrus danicus, Nitzschia delicatissima, Chaetoceros socialis u otras especies de pequeño tamaño del mismo género) rodeado por un plancton gradualmente más diversificado a medida que se aleja del centro. Estas manchas de plancton, si no persisten las condiciones inestables a que deben su origen, evolucionarán hacia una mayor semejanza con el plancton de las áreas vecinas, con las que llegan a confundirse. De la misma manera que los distintos tipos de tejidos de un organismo guardan unos con otros relaciones espaciales bien definidas, existe cierta regularidad en la distribución en el espacio de los distintos constituyentes de las complicadas estructuras planctónicas, íntimamente unida a una no menor regularidad en su evolución o sucesión.

Cualquier generalización a este respecto debe ser formulada de manera muy amplia, en el sentido de los metamodelos de SLOBоDKIN (1958), para que sea aplicable a gran número de estructuras reales. Así, anticipándome en parte a lo qưe se dirá luego, es posible caracterizar por su flujo de energía y por su grado de complicación estructural a poblaciones planctónicas limitadas, es conveniente calificar de menos maduras a las 
que con una estructura más pobre muestran un gran flujo de energía por unidad de biomasa y de más maduras a las que tienen una estructura más rica asociada a un flujo de energía relativamente menor, es general encontrar que el centro de las divergencias está ocupado por poblaciones menos maduras que las periféricas, y es racional postular que las poblaciones menos maduras proponcionan energía a las más maduras y que la tendencia natural en todas las poblaciones es hacia un aumento de la madurez, aumento que purede ser impedido por la persistencia de fluctuaciones en diversos factores del ambiente. Se trata, en suma, de deducir generalizaciones de las observaciones empíricas y buscar a aquéllas una explicación razonable en los principios de la física y de la biología.

Si se alcanza un modelo coherente, es posible examinar de nuevo el significado de las distribuciones estadísticas de las distintas variantes consideradas en cada muestra. Los puntos de vista sintéticos, centrados al nivel del ecosistema, se pueden conciliar con los modelos que proporciona una simple elaboración estadística, del tipo de las usadas por los que rehúsan sistemáticamente considerar como eje de la ecología el estudio de los ecosistemas.

No es inútil recordar que este tipo de estudios ofrece perspectivas interesantes. Las correlaciones funcionales entre diversidad, composición de pigmentos y producción por unidad de biomasa permiten deducir aproximadamente unos valores de otros cuando los datos que se poseien son incompletos y también tener una idea de la distribución de las poblaciones de animales utiles y de su explotabilidad. Indudablemente, hace falta trabajar intensamente en este sentido. Por otra parte, las regularidades observadas en la sucesión ecológica y en las relaciones dinámicas entre los elementos del ecosistema -que hallan expresión también en su estructura- han de constituir el fundamento de cualquier proyecto de predicción. Finalmente, desde el punto de vista de la biología general, tiene gran interés la comparación entre la evolución y organización de las estructuras planctónicas a pequeña escala y los procesos de crecimiento y organogénesis en embriones y tumores. En todos los carsos el mayor flujo de energía se da en las partes menos organizadas y la "explotación» o inhibición de estas partes menos maduras por las partes mús maduras, cuando es posible, constituye la base de todo aumento de organización.

\section{DISTRIBUCIONES DE FRECUENCIA EN SERIES DE MUESTRAS DE PIMANCTON}

Origen verosimil de la normalidad de las distribuciones después de su transformación logaritmica. - Una forma habitual de la aplicación de los métodos estadísticos a la planctología es la siguiente: Se dispone 
de una serie de muestras de plancton y de los correspondientes recuentos de organismos. Las muestras ban sido obtenidas en un universo» constituido por un volumen de agua marina y de ordinario las estaciones de captura se han dispuesto uniformemente espaciadas y las fechas en que se han efectuado las pescas uniformemente equidistantes en el tiempo; por ejemplo, una estación cada kilómetro y repetida cada 15 días. A los fines de su elaboración estadística es habitual que se reúnan las muestras perdiéndose las relaciones de proximidad que guardaban entre sí en el espacio. Sin embargo, la estadística dispone de recursos para incluir el factor topográfico o espacial (cf. BARTLETT, 1960). Muchos estudios estadísticos se encaminan a averiguar si la distribución de los individuos de una o de muchas especies en las muestras, es compatible con la hipótesis de una distribución uniforme en el espacio. La respuesta, como es de esperar, es que la distribución del plancton se aparta siempre significativamente de la hipótesis de una distribución homogénea (BARNES, 1953; Barnes \& Hasla, 1957, etc.). Puede aplicarse el análisis de la variancia para ver en qué grado puede atribuirse a cada una de las variables consideradas : localización horizontal, profundidad, tiempo, etc.,' las variaciones que se observan en la concentración de una especie o de un ćonjunto de especies en las distintas muestras estudiadas.

Precisamente el análisis de la variancia requiere una distribución nórmal de los valores dentro de la serie total o, por lo menos, que la variancia se haga independiente de la media. No es éste el caso en las series de recuentos de plancton. Con el objeto de normalizar las distribuciones se recurre a transformar los datos (BARNES, 1952 ; CAssie, $1962 b$ ). Sie han propuesto varias transformaciones y cada una de ellas se ajusta al particular tipo de distribución que tengan los datos antes de su transformación en una distribución normal, así, por ejemplo, para pasar de una distribución binominal negativa — si se supone que los recuentos en la serie de muestras de plancton se ajustan a ella— a una distribución normal, se hará uso de una expresión hiperbólica bastante complicada y una simplificación de esta expresión, que parece no lleva consigo una pérdida excesiva de precisión, consiste en usar como dato transformado simplemente el logaritmo del dato original (Winsor \& CLARKe, 1940).

En este caso se tiene la llamada transformación logaritmica, cuyo uso es bastante corriente en los estudios del plancton, pues proporciona distribuciones aproximadamente normales para los datos transformados, de forma que sin más pueden ser utilizados en el análisis de la variancia de los mismos. Un inconveniente aparece para los valorez cero, cuyo logaritmo no tiene sentido. Pero una forma de la transformación logarítmica puede ser $x^{\prime}=\log (x+c)$, en que $x$ es el dato original, $x^{\prime}$ el dato transformado y $c$ una constante.

El empleo de la transformación logarítmica se basa en el supuesto 
que los logaritmos de los valores que nos dan los recuentos o densidades de plancton se distribuyen normalmente. El relativo éxito de la transformación logarítmica entre los planctólogos se puede deber en parte a que aquel supuesto se cumple a menudo. Podemos preguntarnos la razón de ello.

Es conveniente continuar la discusión en presencia de algún ejemplo real, como los representados en las figuras 1 y 2 . En ambos casos tenemos series de 81 valores que corresponden al resultado de recuentos en 27 estaciones $\mathrm{y}$ en tres fechas consecutivas. Si tomamos los logaritmos de estos valores, las distribuciones son aproximadamente normales, como puede verse en los respectivos gráficos en que las muestras se distribuyen por los logaritmos de sus densidades (abscisas). Cuando en lugar de trazar la curva de su distribución se traza la curva de los valores acumulados, empleando papel con escala de la distribución normal de probabilidades, el resultado ha de ser una recta si la distribución es "lognormaln ; puede verse que las distribuciones empíricas no se alejan mucho de este caso.

Cuando los datos reales se pasan sobre un cartograma, se manifiesta una y otra vez un tipo común de distribución. Cada especie se encuentra con gran abundancia en un área restringida y en la periferia de la misma su abundancia decae de manera exponencial negativa o logarítmica. Este tipo básico de distribución es general en ecología. Una explicación que los planctólogos acostumbran dar es que las condiciones óptimas para el desarrollo o para la acumulación de los individuos de una especie se dan en lugares bastante limitados y definidos del espacio y que el crecimiento de las poblaciones es exponencial, como el interés compuesto, desparramándose los individuos alrededor del área de condiciones de vida adecuadas siguiendo las leyes de la difusión, que conducen a un decrecimiento centrifugo de la densidad de acuerdo también con una función exponencial negativa. En estas condiciones se hace referencia a la distribución en el espacio ; pero lo mismo puede aplicarse a la distribución en el tiempo. Las poblaciones varían a lo largo del tiempo de manera exponencial y esto es lo habitual en las poblaciones planctónicas sometidas a fuertes fluctuaciones de densidad.

En todo caso, a puntos de muestreo situados equidistantes en el espacio o en el tiempo, es decir, según los términos de una progresión aritmética, corresponden poblaciones cuyas densidades es de esperar varíen en progresión geométrica. No es de extrañar, por tanto, que a una serie de muestras obtenida según las técnicas usuales, en puntos aproximadamente equidistantes en el espacio y en el tiempo, corresponde una distribución aproximadamente lognormal de las densidades de organismos de cada especie en las muestras de la serie.

Esta distribución aproximadamente lognurmal es consecuencia del 

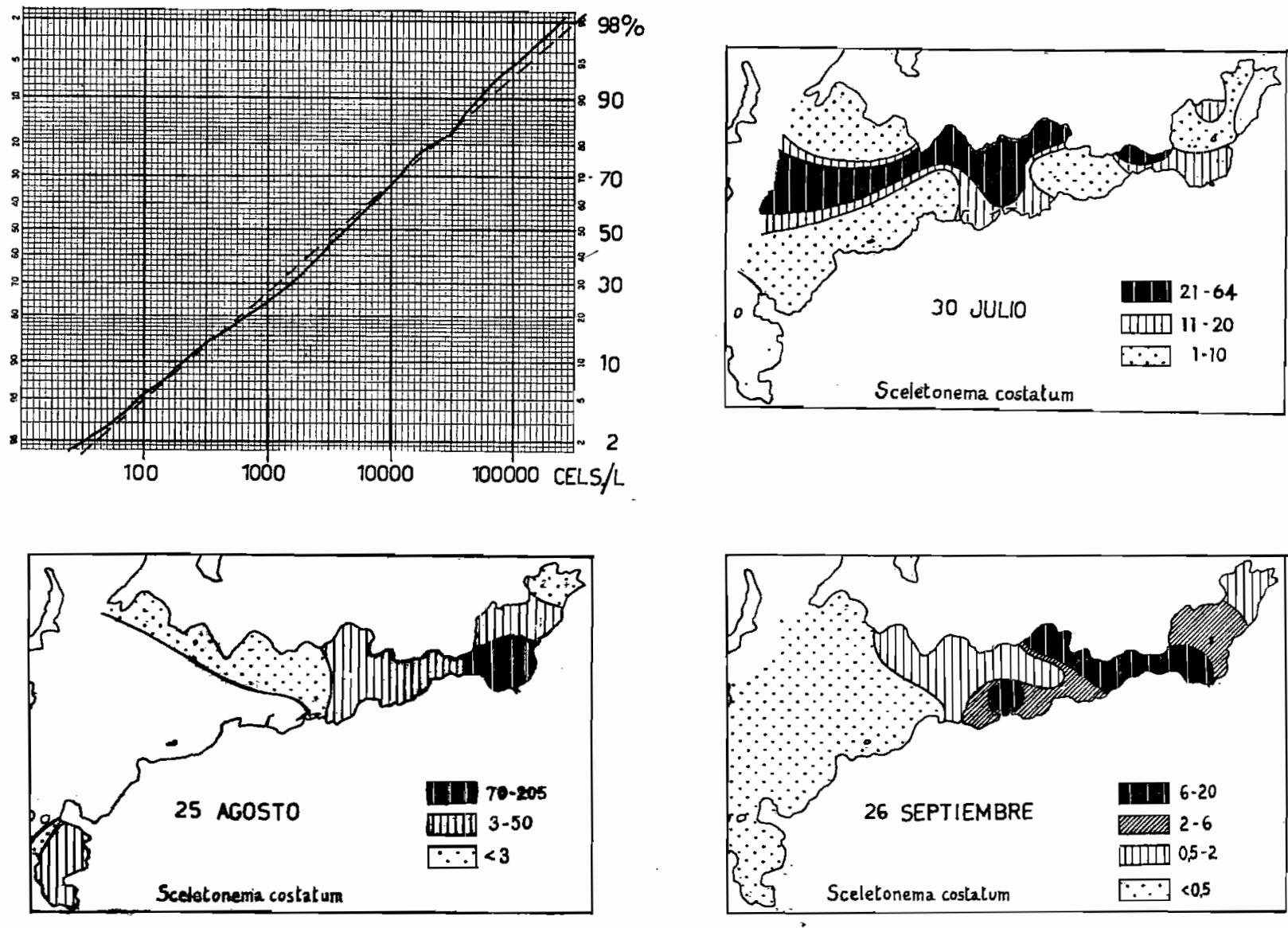

Fig. 1. - Distribución de la diatomea Skeletonerna costatum en las aguas superficiales de la Ría de Vigo en tres fechas diferentes de 1955. En cada ocasión se tomaron muestras en 27 estaciones distribuidas en toda la extensión de la Ría. Ein cada estación se filtró un volumen de agua (200 litros) a través de tela de cerner de la más fina; puesto que una parte de los organismos pudo pasar a través de las mallas de la tela, las cifras que se dan, en número de células por mililitro, representan una estimación mínima, aunque probablemente guardan proporción con la abundancia del alga. En la parte superior izquierda se presenta la distribución acumulada del conjunto de muestras (ordenadas) en función de la concentración de células en cada muestra (abscisas). Abscisas en escala logarltmica, ordenadas en escala de probabilidades. La línea continua es la distribución de las muestras; la línea de trazos es una recta interpolada a ojo. 

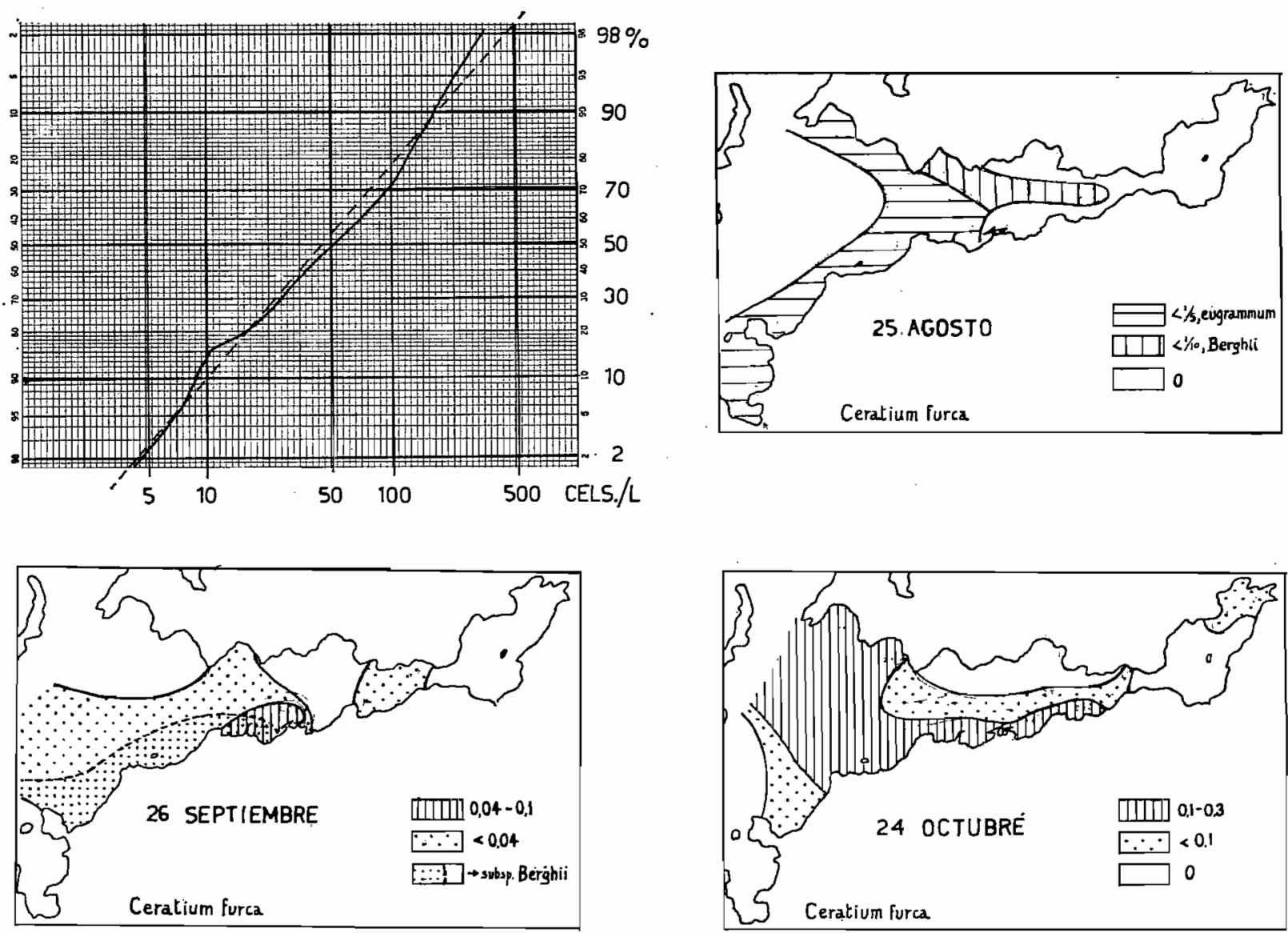

Fig. 2. - Distribución de la dinofiagelada Geratium furca en las aguas superficia'es de la Ría de Vigo, en tres fechas diferentes de 1955. En cada ocasión se tomaron muestras en 27 estaciones distribuidas sobre toda la-extensión de la Ría. En cada estación se filtraron 200 litros de agua a través de la tela más fina usada en la confección de redes de fitoplancton. Las concentraciones se dan en células por mililitro $\mathrm{J}$ son estimaciones minimas por la posible pérdida de alounas célolas a través de las mallas d la red. Se ha distinguido la lubespie bor

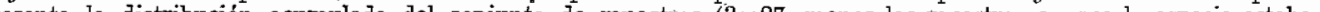
quier normal. La línea continua corresponde a la distribución de las muestras; la línea de trazos es una recta interpolada a ojo. 
carácter logarítmico o exponencial de procesos biológicos fundamentales : de la multiplicación de los organismos y de su difusión. Pero debemos esperar que nunca será exactamente lognormal, pues no hay razón para esperar una distribución normal de las tasas de multiplicación y de difusión, si no es en condiciones muy especiales, por ejemplo, cuando existen múltiples gradientes suaves y entrecruzados en la intensidad de los distintos factores físicos y en un espacio extenso.

El tipo de distribuciones estadísticas que se manifiestan en las series de muestras de plancton se relaciona además con el hecho de que las distintas muestras no pueden compararse a bolas sacadas sucesivamente de un bombo de la lotería, sino que son elementos elegidos con mayor o menor arbitrariariedad (al fijar la situación de las estaciones y las fechas de las operaciones) de un sistema estructurado. Cada uno de los valores de la serie ha de verse en su propio marco espacial y temporal. La probabilidad de presencia de determinada especie es mayor cuando en una estación inmediata dicha especie es abundante. Estas consideraciones conducen a aceptar distribuciones del tipo llamado acontagiosos. Por tanto, este hecho es reconocido generalmente por todos los que sie han ocupado de los problemas de la estadística de plancton. Cassie (1959) señala expresamente que la abundancia numérica de una especie en una región puede no ser independiente de la abundancia en regiones adyacentes. Cushing (1953) ha empleado el análisis de la variancia para determinar los límites relativamente discontinuos entre manchas de plancton. Cualquier aceptación de manchas o heterogeneidades en la distribución del plancton lleva implícito el reconocimiento de una distribución de tipo contagioso. Este tipo de distribución, precisamente, explica también la frecuente normalidad de las distribuciones después de la transformación logarítmica de los datos.

Relaciones entre los organismos y los factores ecológicos del ambiente. - Una de las tareas en la que los ecólogos han invertido más tiempo es el establecimiento de relaciones cuantitativas entre la densidad de la población de una especie o de un conjunto de especies y la intensidad de alguno o algunos de los factores en que descomponemos la acción del ambiente sobre los seres vivos. Los datos obtenidos en el área de Castellón, especialmente durante los años 1960 a 1962 , en que fue estudiada con particular intensidad (Hrrrera \& Margalef, Margalem \& HERRERA, en prensa) proporcionan un material abundante para ensayar isobre él el descubrimiento de relaciones entre densidades de determinada esplecie y densidades de otras especies, o bien temperaturas, salinidades, fosfatos o iluminación.

Estos estudios se pueden llevar a cabo por los procedimientos estadísticos de cálculo de correlaciones, sencillas o múltiples y por el análisis 
factorial. CAssie ha calculado regresiones múltiples en ejemplos concretos del plancton. El cálculo de correlaciones en distintos fenómenos naturales no desemejantes a los ejemplos que ofrece el plancton, ha sido criticado por Cook (1960) y KINSMAN (1957), pero no hay inconveniente en emplear este método si no se olvida que una asociación estad́stica no significa necesariamente una asociación funcional. En la mayor parte de los casos basta iniciar el análisis con diagramas de puntos, como los empleados por Bary (1958), SMAYdA (1958), Williamson (1961), Moore (1952) y otros (diagramas de temperatura, salinidad, plancton [T-S-P]).

Se han compilado numerosos diagramas de este tipo a base de los datos que se tenfan a disposición, procedentes del área de Castellón, publicados, en prensa, o inéditos. Los diagramas de puntos dan una idea tan pobre de las correlaciones existentes que no estimulan precisamente a aplicar procedimientos más exactos de cálculo. Así, al considerar la relación con la temperatura, se observa que muchas diatomeas son más frecuentes entre límites estrechos de temperatura; pero si se extiende la serie de datos a otras aguas más alejadas, esta relación se esfuma considerablemente y la correlación resulta muy vaga. Pronto se echa de ver que las diatomeas, si son más abundantes en las aguas más frías, lo son porque dichas aguas, en esta área, contienen mayor concentración de fosfato y que la dependencia con respecto a la temperatura es casi totalmente espuria. Lo mismo vale con respecto a la salinidad. En todos los laboratorios donde se cultivan algas del plancton se conoce la extremada eurihalinidad de la mayor parte de las especies, de manera que las aparentes correlaciones que a veces se manifiestan entre densidad de la población de cierta especie y salinidad son, las más veces, indirectas y sin el sentido biológico que desearlamos aprehender para tener una idea del mecanismo de la sucesión y distribución del fitoplancton.

En el caso de la temperatura y la salinidad, la dependencia se establece a veces entre la presencia de ciertas especies y la ausencia o presencia de gradientes verticales en los valores de aquellas variables. De manera que, en ciertas ocasiones, será aconsejable buscar las correlaciones no con los valores locales de temperatura y salinidad, sino con sus derivadas en relación con la dimensión vertical.

Las variables ambientales que proporcionan correlaciones biológicamente más significativas con la densidad de las poblaciones del fitoplancton, como son la intensidad de iluminación y la concentración de elementos nutritivos (concretamente, de fosfato) son, a su vez, las que manifiestan una reacción más intensa de los propios organismos. La concentración de fosfato regula las poblaciones de algas; cuando éstas se desarrollan consumen rápidamente el fosfato presente y lo que antes era una correlación positiva se convierte en negativa. La relación entre las algas y la luz queda deformada por la sedimentación del plancton, de 
manera que plancton producido en capas iluminadas aparece más tarde concentrado en capas menos iluminadas. En tales condiciones se hace idiffcil encontrar correlaciones estadísticas sencillas. Sin embargo, pueden existir correlaciones entre la intensidad de los factores y la tasa de cambio de la población, o sea, una derivada con respecto a tiempo ; pero no entre la intensidad de aquellos factores y la densidad de la población en un punto y tiempo determinados.

La conclusión es que, desde el punto de vista de la biología del plancton, es empresa interesante calcular correlaciones entre características de sus poblaciones y características del ambiente físico, pero que estas correlaciones más bien deberán establecerse entre derivadas con respecto a tiempo (tasas de cambio) o a espacio (gradientes), o entre magnitudes que tengan aproximadamente tal carácter. Así, por ejemplo, podemos estudiar la correlación entre el gradiente vertical de densidad y la tasa de aumento de una población planctónica. La primera puede ser representada por la estabilidad y la segunda por el índice $D_{430} / D_{\text {sos }}$ de los pigmentos, que es tanto mayor cuanto más reducida es la tasa de mụltiplicación, en general. En una serie de datos sobre el fitoplancton de un área poco profunda (generalmente hasta 20 metros) situada al sur de Puerto Rico tenemos, como ejemplo :

\begin{tabular}{|c|c|c|c|}
\hline Estabilidad & $\begin{array}{l}\text { Valores } \\
\text { indice }\end{array}$ & $\begin{array}{l}\text { medios del } \\
\mathrm{D}_{340} / \mathrm{D}_{665}\end{array}$ & $\begin{array}{l}\text { Numero de } \\
\text { estaciones }\end{array}$ \\
\hline & & 4,54 & \\
\hline Estabilidad nula o positiva & . . & 5,08 & 33 \\
\hline
\end{tabular}

Ejemplos parecidos se pueden elaborar a partir de los datos contenidos en las publicaciones mencionadas de HerRera y Margalef.

Ecosistemas isótropos y anisótropos. - Una población uniespecífica se distribuye de manera heterogénea y el modelo más simple de distribución incluye un volumen limitado donde la especie alcanza una densidad máxima, rodeada por volúmenes más o menos concéntricos en los que la numerosidad de la especie decrece con la distancia de manera aproximadamente exponencial. La forma de los volúmenes envolventes puede ser esférica, semiesférica o irregular.

Imaginemos un ecosistema formado por la superposición de un número ilimitado de poblaciones uniespecificas, cada una de ellas distribuidas en la forma que queda dicha. Supongamos, además, que los centros de máxima abundancia de cada una de las especies no coinciden, 'sino que se encuentran sembrados en el espacio de manera que, en primera aproximación, podemos considerar al azarn. La planctología ofrece constantemente ejemplos de este tipo, como el de la figura 3. 
De una manera más esquemática, una población de estas caracteristicas puede representarse conforme se ha hecho en la figura 4, a la izquierda. Una población mixta de este tipo tendrá, por lo que a densidad total y distribución de individuos en especies se refiere, unas características semejantes en todos los puntos de su extensión, a pesar de estar 'formada por la suma de un número grande de poblaciones cada una de
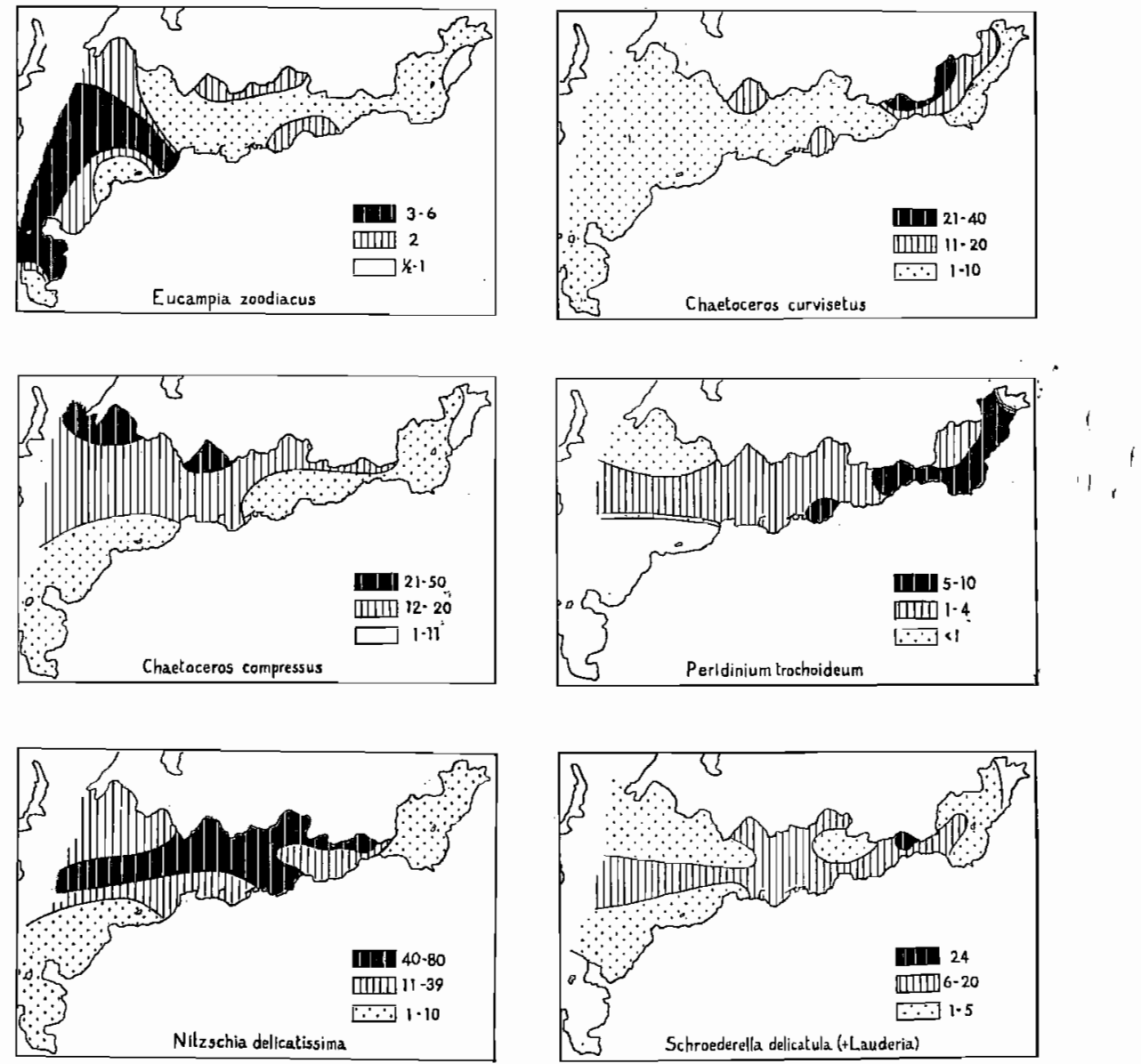

Fra. 3. - Distribución de 6 especies del fitoplancton en las aguas superficiales de la Ría de Vigo, el 30 de julio de 1955. Cada cartograma se basa en el estudio de 27 estaciones distribuidas por toda la extensión de la Rí. Como que las muestras se obtuvieron filtrando agua a través de una red fina, hubo cierta pérdida de células y las densidades que se dan, en células por $\mathrm{ml}$, son estimaciones minimas. Junto con Schroederella delicatula se incluyeron algunas células de identificación dudosa, posibles Lauderia borealis. El gráfico presenta un ejemplo de falta de coincidencia on los centros de máxima abundancia de una serie de especies cuyo conjunto constitula una proporción importante del fitoplancton total. 
las cuales muestra una distribución significativamente no uniforme. 'Puede ser conveniente calificar de isótropa a una población mixta de estas características. Una población isótropa no es una población uniforme, sino heterogénea, pero con una estructuración uniforme de su heterogeneidad en todo el espacio por el que se extiende.

Sigamos considerando la población mixta formada por un número indefinido de especies, cada una de ellas representada por un número semejante de individuos, cuya densidad decrece exponencialmente a partir de un centro de máxima densidad, y que estos centros de máxima densidad de unas y otras especies son equidistantes. Consideremos a la población extendida en dos dimensiones, es decir, aceptando que verticalmente carece de la estructura que manifiesta en el plano horizontal. Es fácil extender la hipótesis a una estructura en tres dimensiones. Situándonos en un centro de máxima denisidad $\left(N_{a}\right)$ de una especie $a$, tendráamos la siguiente composición en la población mixta: $N_{a}$ individuos de la especie $a$. Si la distancia entre los centros de máxima abundancia de las especies es $x$, habrá 6 especies representadais por $N_{a} e^{-g k}, 12$ especies representadas por $N_{a} e^{-2 k x}$ individuos, y así sucesivamente. En otros términos : una especie será muy abundante y a ella se añadirán números progresivamente crecientes de especies cada vez menos abundantes, de forma que la distribución de individuos en especies se aproxima a una de las series logarítmicas que se han puesto de manifiesto como de ocurrencia frecuente en los estudios sobre diversidad biótica. En este trabajo, como en anteriores, la diversidad se expresará según la fórmula $' D=-\Sigma p_{i} \log _{2} p_{i}$ en que $p_{i}$ son las probabilidades de ocurrencia de cada una de las especies de la población mixta $\left(\Sigma p_{i}=1\right)$. Se comprende que, en semejante población, la diversidad tendrá valores parecidos en todo el espacio por el que aquella se extiende y será tanto más uniforme cuanto mayor sea el número de especies, que se ha considerado ilimitado, y cuanto más bajos sean los valores de $k$. Los puntos de mínima diversidad, en todo caso, coincidirán con los centros de máxima abundancia de cada una de las especies, de manera que las líneas que unan los puntos de diversidad máxima tendrán la forma de un retículo, semejante a las paredes de cera de un panal, que separará celdas, cada una de las cuales eștará caracterizada por la dominancia de una especie particular.

Otro caso más general es que las distribuciones de las distintas especies no; sean comparables ni se repartan con uniformidad en el espacio. Ahora cada punto del volumen considerado no sólo tiene una población diferente, sino además una diferente estructura de la población, un tipo diverso de la distribución de individuos en especies. Una población mixta de este tipo, que se puede calificar de anisótropa, es la representada gráficamente a la derecha de la figura 4. En una población anisótropa existen considerables diferencias locales en la diversidad y su anisotropía 

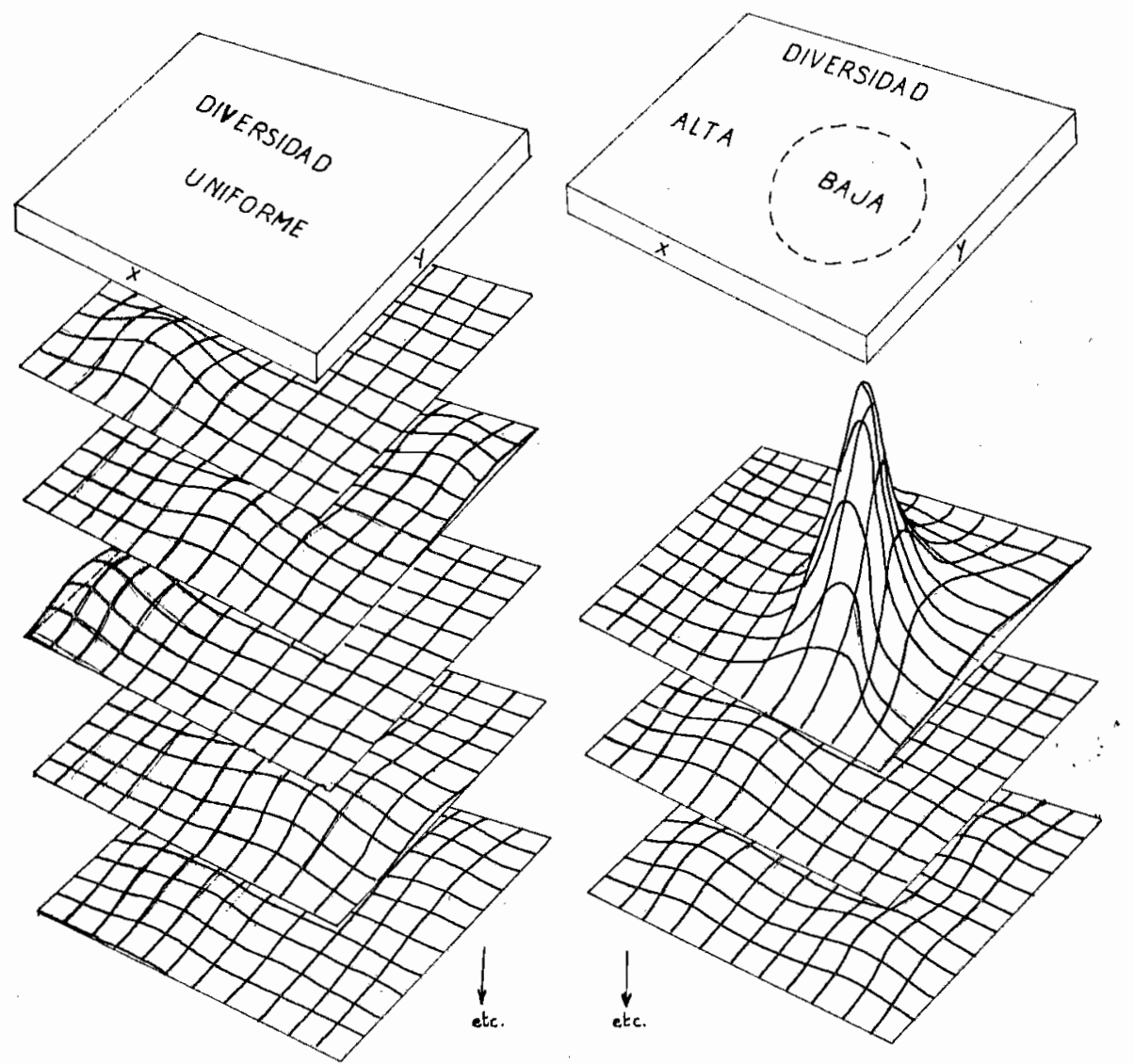

FIG. 4. - Representación ideal de distribuciones de plancton isótropa (a la izquierda) y anisótrope (a la derecha). En cada caso se considera la distribución solamente en dos dimensiones $(x, y)$; este gráfico podrfa representar la distribución del plancton en aguas superficiales. Cada distribución de conjunto se considera formada por la superposición de un número indefinido de distribuciones unispecificas, de las que se representan 5 a la izquierda y sólo 3 a la derecha. En el ejemplo de la izquierda, los tipos de distribución de las distintas especies son comparables, aunque no coin. ciden, puesto que los centros de máxima abundancia de las diferentes especies se distribuyen de manera más o menos uniforme y al azar sobre el plano. El resultado es una población mixta que tiene una densidad total aproximadamente uniforme en toda el área y cuya distribución de individuos en especies, expresada por un indice de diversidad cualquiera, es también uniforme. En el ejemplo de la derecha, cierta especie presenta un máximo muy notable en un lugar definido del área, del que estún más o menos alejados los puntos donde alcinzan su míxima población las otras especies menos numerosas. La densidad de la población total puede ser uniforme aproximadanente sobre toda el área estudio, o no serlo; pero en todo caso la distribución de individuos en especies es desigual, y la diversidad calculada sobre dicha distribución presentará un valor mínimo precisamente en el lugar donde se manifiesta el fenómeno de dominancia de una especie (o de unas pocas especies). Las coordenadas $x, y$ en este ejenıplo pueden colresponder a coordenadas métricas, por ejemplo, a la longitud y a la latitud en un área marina; pero el espacio métrico puede sustituirse por un espacio ecológico, en el que $x$, y representen valores de variables ambientales, por ejemplo, para mencionar los factores más usados por los ṕlanctólogos, temperatura y salinidad, o bien, para mencionar factores realmente más importantes, concentración de fosfatos e iluminación. 
puede representarse por medio de curvas o superficies envolventes que unen los puntos de igual diversidad. Perpendicularmente a dichas superficies de igual diversidad, que corresponden a las que PatTEN llama isoentrópicas, se extienden gradientes que van de los espacios donde la diversidad de la población es mínima a aquellos en los que es máxima. De acuerdo con dichas superficies y gradientes, resulta conveniente distinguir en una población anisotrópica porciones menos maduras (baja 'diversidad) y porciones más maduras (alta diversidad).

La estructura elemental más importante en las poblaciones anisótropas consiste en un foco o celda de mínima divensidad, y mínima ma'durez, donde una o pocas especies se muestran dominantes, con un número muy elevado de individuos, cuya concentración suele caer rápidamente hacia la periferia ( $k$ elevado). Los lugares de máxima diversidad, o máxima madurez, raramente son epuntiformes» $\mathrm{y}$ suelen extenderse linealmente o en forma de retículo.

Transposición de las distribuciones del espacio real al espacio 'ecológico. - En la forma normal de obtener y presentar los resultados del estudio del plancton, las distribuciones de las poblaciones uniespecíficas o mixtas se describen en relación con el espacio métrico, empleando las escalas que se consideran apropiadas. Para el estudio de la sucesión de poblaciones, podría ser conveniente en algunos casos introducir otro sistema de coordenadas, deformables según los movimientos del medio y que se apartarian, por lo general progresivamente de las coordenadas geográficas, con las que se hicieron coincidir al principio. Parece que las propiedades dinámicas de las poblaciones se pueden estudiar con cualquier sistema de referencia, mientras no se quebranten las relaciones topológicas. Se corre el riesgo de hacerlo en superficies de discontinuidad donde ocurran deslizamientos relativos entre dos masas de agua diferentes.

Puesto que la intensidad de los distintos factores ecológicos suele variar de manera gradual, otra posibilidad consiste en cartografiar las distribuciones de las especies, no con respecto a las tres dimensiones del espacio real, sino con respecto a $n$ dimensiones que representan las intensidades de otros tantos factores, es decir, trasponer las distribuciones a un espacio ecológico, como el empleado por Hotoninson (1957) al discutir su concepto de nicho ecológico. En la figura 4 puede imaginarso que las coordenadas $x, y$, en lugar de representar las dos dimensiones del plano horizontal representan las intensidades de dos factores determinados, por ejemplo, iluminación y concentración de fosfato.

Veamos cómo aparecerán las poblaciones isótropas y anisótropas en un espacio ecológico. Las distancias que separan los centros de máxima abundancia de las distintas especies permitirán atribuirlas a unos mismos 
nichos ecológicos o a distintos nichos ecológicos, si es que se juzga útil conservar el concepto de nicho ecológico. Tal vez en las relaciones entre nichos se pueda basar alguna predicción. Una población heterogénea e isótropa puede mantenerse como tal en un ambiente caracterizado por el entrecruzamiento en distintas direcciones de diversos gradientes de factores ambientales; pero en un ambiente más uniforme (entonces las distribuciones de las especies ise superpondrán en el espacio ecológico) dicha población evolucionará probablemente hacia una mayor uniformidad, conservándose, naturalmente, isótropa. En una población anisótropa, los centros o nodos de mínima diversidad y mínima madurez coinciden con aquellos puntos del espacio ecológico en que existe una mayor disponibilidad de recursos utilizables en la producción, donde el flujo potencial de energía es mayor, por ejemplo, en aguas poco pobladas, con poca materia orgánica, ricas en elementos nutritivos inorgánicos e intensamente iluminadas. En un espacio ecológico, cuyas coordenadas corresponden a intensidades de distintos factores ecológicos, se pueden definir los distintos lugares por las oportunidades no usadas de producción que brindan y trazar superficies correspondientes. Pues bien, los nodos o centros de mínima madurez en una población anisótropa corresponden a los valores máximos de aquella oportunidad no aprovechada para producir. Es de suponer que en el espacio ecológico que corresponde a una población isótropa, la capacidad no aprovechada de producir está más uniformemente repartida.

Esta discusión es muy teórica y, por ello, de escasa aplicación inmediata. Sin embargo, no se ha suprimido porque puede permitir aclarar algunos de los aspectos de cualquier transposición (amapping») de una población sobre coordenadas que representen variables ecológicas (por ejemplo, los diagramas T-S-P) y discutir la conveniencia de seguirlos utilizando y su posible significado. Por otra parte, puntos de vista relacionados con éstols se han empleado con cierto éxito en el análisis de comunidades, por ejemplo, el análisis nodal de WiLliams \& LamberT (1961).

\section{RESUMEN DE LOS TIPOS DE DISTRIBUCION DE LAS POBLACIONES PLANCTONICAS}

A. Distribución uniforme u homogénea; las diferencias entre las muestras son las que deben esperarse del error técnico del muestreo.

a. Para una especie.

b. Para muchas especies.

Los dos casos son irreales.

$B$. Distribución heterogénea, significativamente distinta de la hipótesis de una distribución uniforme.

a. Para una especie. Es el caso normal.

b. Para muchas especies : 
1. Semejante para todas ellas. Caso irreal.

2. Diferente para unas y otras especies. Es el caso normal. Pueden hacerse dos subdivisiones, atendiendo a diferentes eriterios. Por la forma de los gradientes :

(a) La densidad de las especies varla gradualmente en el espacio.

(b) La densidad de las especies presenta cambios bruscos o discontinuidades acumuladas a lo largo de ciertas superficies. $Y$ por la estrustura de las poblaciones:

[a] Poblaciones isótropas; heterogéneas, pero con la distribución de individuos en especies semejante en toda su extensión.

[b] Poblaciones anisótropas; el tipo de estructura de la población mixta varía de un lugar a otro y las propiedades sintéticas de la población, como son organización y flujo de energia, varían localmente en su intensidad.

La estructura de las poblaciones mixtas puede ponerse en relación con la diferenciación del medio físico. En un ambiente uniforme, las poblaciones pueden ser teóricamente uniformes; pero prácticamente son divensas, aunque el agua manifieste cierta intensidad de mezcla (RYTHen \& HULbURT, 1960). Un ambiente no uniforme puede mostrar una, variación gradual de la intensidad de sus factores ambientales, o bien superficies de discontinuidad, horizontales (picnoclinàs) o verticales (frehtes marinos). Pero la estructura de la heterogeneidad en las poblaciones nó coincide necesariamente con la estructura de la heterogeneidad en el ambiente, aunque generalmente existe cierto grado de correspondencia.

Tanto la estructura del ambiente como la de las poblaciones muestra una amplia escala o espectro de dimensiones. Una vasta zona de afloramiento de aguas profundas incluye remolinos menores, con pequeñas convergencias y divergencias o irregularidades de otro tipo. De igual modo, una población anisótropa que, en sus líneas generales presente un gradiente de madurez según un sentido definido, muestra, superpuesta a esta disposición general, centros subordinados de mayor o menor madurez que complican el detalle de la estructura total y semejante análisis puede llevarse hasta los más pequeños espacios que es posible muestrear separadamente.

\section{ESTRUCTURA DE LAS POBLACIONES MIXTAS}

Complejidad. - En trabajos anteriores (Margalew, 1957 b) se ha dedicado considerable espacio a examinar la diversidad biótica o complejidad de una población mixta, tal como resulta cuando se considera la distribución de individuos en especies. Eis un carácter que se puede examinar independientemente de cualquier hipótesis que se formule respecto al ajuste de las distribuciones naturales observadas a ciertas distribuciones estadísticas. Eis aconsejable expresarla con alguna fórmula deri- 
vada de la teoría de la información, por ejemplo, en bits por célula o por individuo. Esta unidad es conveniente porque es intuitiva, en efecto, expresa el número medio de decisiones binarias que son necesarias, o de disyuntivas que es preciso resolver, para identificar la especie de uno cualquiera de los individuos de la población mixta. Como es natural, dicho número de decisiones ha de ser mayor en una población que contenga más especies y cuyas abundancias sean menos desiguales. Tal población se dice más diversa y la medida de su diversidad, en bits por célula, por ejemplo, tranténdose de fitoplancton, es más alta.

La expresión copiada en un apartado anterior, $-\Sigma_{i} p_{i} \log _{2} p_{i}$, puede considerarse como una función que permite discriminar entre diversas poblaciones en atención a las condiciones de dominancia que en las mismas existen; sus valores son bajos donde existe dominancia de una o pocas especies. Son bajos, por tanto, en los lugares donde se da la máxima abundancia de cada una de las especies, principalmente cuando su densidad alcanza valores absolutos muy altos, como suele ocurrir en puntos singulares de la distribución de poblaciones anisótropas.

Pero la distribución de unas especies no puede consideranse, como hasta ahora hemos hecho, independiente de la de otras. Además de una posible acción paralela del medio físico sobre todas, existe una interacción entre unas y otras especies, basada en la operación de un número ilimitado de fenómenos vitales. Vista desde esta nueva perspectiva, la diversidad biótica tiene mayor interés por expresar el número de relaciones posibles, que por referirse al número de elementos y a las combinaciones que con ellos pueden hacerse. Fn una población de alta diversidad es posible una mayor variedad de tipos de relaciones entre unas y otras especiels, o entre ellas y el medio. El que un ecosistema tenga alta diversidad significa que su funcionamiento puede alcanzar un grado mucho más elevado de complicación. Pueden existir en él mayor número de circuitos recurrentes (afeedback») y la diversidad se convierte en una medida de la capacidad del sistema para contener o construir mecanismos de regulación. Por lo que se refiere al medio marino, se ha reconocido que las poblaciones más estaioles de aguas cálidas son más diversas (HEINRICH, 1962) y en el medio terrestre se señala que las grandes fluctuaciones de biomasa ocurren en comunidades de baja diversidad (PIMENTEL, 1961).

En este sentido el concepto de diversidad de un ecosistema es comparable con el de complejidad de una red nerviosa, una calculadora electrónica o cualquier otro artefacto de la cibernética. En semejantes casos un sistema miás complejo —más diverso- els más estable, en el sentido de presentar menores fluctuaciones internas, goza de mayor capacidad de homeostasis y hasta de autolreparación. La energía que necesita para su sorstén o su funcionamiento cualquiera de estos sistemas, por unidad 
de elemento constitutivo, es menor cuando el sistema es más complejo. Las mismas regularidades se cumplen en los ecosistemais ; aunque conviene señalar diesde ahora que el grado de organización no sólo depende de la complejidad o diversidad en el momento actual, sino también de su persistencia a través del tiempo.

El espectro de la diversidad biótica y su evolución. - En otros trabajos (MARgaLEF, 1957 b , 1962) se ha discutido el espectro de la diversidad. Si, a partir de un individuo inicial se van tomando muestras cada vez más amplias, la diversidad relativa (por individuo, por unidad de volumen) varía. Si la diversidad deja de aumentar al ampliar la muestra, o al confundir dos muestras, existe una correlación perfecta en la distribución de todas las especies en entrambas. Por esto las variaciones en la diversidad son utilizables para el estudio de la estructura de la población en el espacio. Las variaciones en la diversidad dependen, además, de la dirección y del sentido según el cual se amplia la muestra. La diversidad tiene, por tanto, carácter vectorial. La función que describe la variación de la diversidad al ir de $x_{1}$ a $x_{2}$, o al ampliar la muestra gra'dualmente de $x_{1}$ a $x_{2}$, es distinta de la que corresponde al paso en' sentido inverso, o sea, de $x_{2}$ a $x_{1}$. Esta propiedad se reflejia también én 'otros métodos estadísticos propuestos para el estudio de las estructuras 'de las poblaciones, por ejemplo, en el análisis de las relaciones de vecin'dad entre dos especies, aplicando la prueba del $\chi^{2}$ a una tabla de contingencia (PIELOU, 1961).

A medida que un ecosistema se desarrolla, aumenta su diversidad. Ios distintos niveles tróficos que usan sucesivamente la energía que entra en el sistema se añaden forzosamente de manera consecutiva; los fitófagos después de los vegetales, los zoófagos después de los fitófagos, los parásitos no antes de isus hospedadores, etc. Consideraciones teóricas piden también que toda sucesión ecológica represente un aumento del grado de organización y una de las formas en que ésta se manifiesta es en el aumento de la diversidad. La diversidad tiende a crecer en el curso de la isucesión, al aumentar el número de nichos ecológicos. Así razona también Patten (1962).

Sin embargo, la abservación de muestras de plancton lleva a admitir que, en muchos casos, la diversidad disminuye de nuevo hacia una etapa avanzada de la sucesión. El fenómeno se ha de poner en relación con la estructura de la población a una escala más amplia y con una consecuencia de la toma de muestras. Las primeras etapas de una sucesión planctónica muestran una población relativamente uniforme y de baja diversıdad, extendida en una amplia masa de agua. En una segunda fase, la composición de la población sigue siendo relativamente uniforme y su diversidad es más alta. Este tipo de distribución puede atribuirse a la per- 
sistencia de cierto grado de turbulencia. Debe suponerse que para una turbulencia nula, la diversidad seria mínima en cualquiera de las muestras más pequeñas que pudiesen obtenerse independientemente. En este particular momento, el espectro de la diversidad se debe relacionar estrechamente con el espectro de la turbulencia y se poseen algunos datos, que no se han elaborado todavía por juzgarlos incompletos, que así parecen confirmarlo. Más adelante, en las condiciones de mayor estabilidad del medio que constituyen el marco propio de las etapas finales o más maduras de la sucesión planctónica, la población se hace más heterogénea en el espacio, de manera que la diversidad sigue aumentando cuando se estudian muestras suficientemente amplias, pero la diversidad ordinariamente desciende en muestras obtenidas en volúmenes muy restringidos (MARGALEF, 1958, fig. 5). En otros términos, la diversidad ha cambiado de nivel. Su manifestación se traslada a una escala mayor cuando la turbulencia es suficientemente pequeña. Se comprende que cuando se emplean métodos de muestreo que confunden la población de un volumen suficientemente extenso (la red de plancton, por ejemplo, en comparación con la sedimentación del plancton de pequeños volúmenes de agua) la reducción final de la diversidad a pequeña escala puede pasar inadvertida.

Este razonamiento resuelve la paradoja del plancton de HuTCHIN son (1961) y merece la pena insistir con un sfmil. La situación es comparable a una serie de mesas de juego, ocupadas por jugadores con semejantes posibilidades e igual cantidad de dinero. Si las mesas están desligadas, la situación previsible es que, al cabo de cierto tiempo, en cada mesa se alcance la minima diversidad, es decir, que un jugador haya reunido los fondos de todos. Es un ejemplo de la forma de ejercerse la competencia entre especies dentro de un mismo nicho ecológico. Pero si acoplamos las distintas mesas de juego, de manera que un mismo jugador tome parte simultáneamente en distintos juegos, la probabilidad de ser eliminado se reduce y la diversidad se mantiene alta. Un agua turbulenta expone a los organismos sucesivamente a distintas condiciones ecológicas y corresponde al acoplamiento de muchas mesas de juego. Pueden coexistir especies que, asociadas por largo tiempo bajo condiciones constantes, se mostrarían incompatibles. A la vez, la turbulencia mezcla o uniformiza la población en un espacio extenso. El espectro de la diversidad de una población en agua turbulenta se caracteriza por mostrar una diversidad exagerada en celdas de dimensión pequeña $y$, tal vez, una diversidad demasiado pequeña en celdas de gran dimensión, frente al espectro anormals de la diversidad en aguas más estabilizadas, en que la diversidad crece según cierta función de la dimensión de la celda en la que se mide. En un trabajo anterior (MargaLEF, $1957 b$ ) se sugirió que la diversidad, en bits por célula, podía aumentar en función del logaritmo de la amplitud del espacio considerado. 
Otros métodos estadísticos han puesto igualmentie de manifiesto la existencia de distintos tipos de distribución de los organismos en el espacio a lo largo de la sucesión. Así, Kayama (1961) en plantas superiores, señala que las distribuciones, a lo largo de 'la sucesión, se ajustan de manera sucesiva a las de Poisson, Pólya-Eggenbergen, Poisson otra vez, y binomial. Esta's correspondencias, como es natural, pueden facilitar la tarea de buscar algunos factores operativos en la estructuración de la vegetación en las idistintas etapas.

Diferentes niveles de th complejidad. - La forma en que ha sido iniciada la discusión de la distribución de las poblaciones planctónicar, ha conducido de manera natural a hablar de diversidad, de complejidad, con referencia a la distribución de individuos en especies, como si la población estuviera constituida básicamente por individuos y como si los tipos de relaciones que en ella pudieran establecerse fueran solamente relaciones interespecíficas. Pero esta forma de entender la diversidad no es obligada ni tal rez es tampoco la mús conveniente.

En primer lugar se presenta la dificultad de discernir si debemos tomar como unidad el individuo o la célula. Para el fitoplancton el problema se resuelve sencillamente. Expresar la diversidad en bits por célula es práctico y conveniente. Pero la diversidad de un ecosistema ha de réferirse a todos los elementos que en él intervienen, diesde las bacterias hasta los vertebrados y en este momento empiezan a presentarse dudas sobre la conveniencia de elegir una u otra base de referencia. Por otra parte, es imposible efectuar un censo completo de la composición de una población mixta. Sin embargo, la diversidad, la organización de un ecosistema, son características medibles, aunque escapan a nuestras actuales posibilidades de medirlas.

En la práctica se babla de diversidad biótica con referencia a una sección o segmento de la comunidad, sección que se segrega del resto casi siempre en atiención a dos criterios, un criterio taxonómico - diversidad del fitoplancton, idiversidad de las diatomeas, diversidad de la población de copépodos, diversidad de la población de peces- y un criterio derivado del uso de detierminados instrumentos para la toma de muestras —diversidad del fitoplancton de red, diversidad de los peces atraídos por la luz-. En ocasiones, aunque se posea la muestra adecuada, puede ser impracticable calcular con exactitud su diversidad, como, por ejemplo, en ciertas muestras de plancton estudiadas al microscopio de Utermöhl, cuando no es posible una identificación rigurosa de todas las células. El fitoplancton de red contiene una representación despreciable de las bacterias y del nanoplancton y proporciones diversas de las distintas especies del microplancton, en función del tamaño de las células, de la longitud media de las cadenas que aquéllas forman, del previo taponamiento. 
de las mallas de la red por abundantes organismos, etc. Por lo demás, un fitoplanctólogo, acostumbrado a considerar los organismos según sus afinidades taxonómicas, incluirá en sus listas a las nostílucas, por ejemplo, que idesde el punto de vista ecológico son ciertamente animales.

A pesar de la deformada visión que proporcionan los indice de diversidad, tal como se calculan habitualmente sobre el material de que se dispone, y sobre la que se podrían escribir muchas páginas, existen motivos para isospechar que los indices obtenidos proporcionain una idea utilizable de la diversidad del conjunto, especialmente cuando no se olvidan ciertas relaciones biológicas. Laa diversidad de un fitoplancton tiene sentido; pero la diversidad de las poblaciones de diatomeas y de las de dinoflageladas que lo componen, considerada separadamente, no guarda gran paralelismo, como no lo guardan, para dar un ejemplo terrestre, la diversidad en la flora de líquenes y en la fauna de carnívoros de una comunidad. Ello ocurre porque las diatomeas y los líquenes son organismos más abundantes en ecosistemas relativamente poco maduros, mientras que las dinoflageladais y los animales carnivoros son más abundantes en iecosistemas más maduros. Pero hechas estas salvedades, la complejidad inasequible de un ecosistema parece que se refleja en muchos planos o niveles observables sobre los que podemos proyiectar la comunidad por medio de operaciones uniformes.

Las diversidades bióticas que se manejan tienen, pues, el valor de cifras relativas que sirven para comparar a unos ecosistemas con otros, siempre que hayan sido obtenidas con la uniformidad suficiente de méitodo. No ies posible, por tanto, emplear dichas magnitudes en consideraciones termodinámicas como si tuvieran un valor absoluto, ni tampoco incluirlas en comparaciones con artefactos cibernéticos equiparando a los individuos contados con neuronas, o con válvulas electrónicas.

La complicada estructura de un ecosistema se refleja en planos muy diversos. Autories japoneses han estudiado la diversidad en la distribución ide biomasas por especies, en vez de la forma habitual de calcularla sobre la distribución de individuos en especies. Es posible también cartar por encima de las diferencias ientre especies y apreciar una diversidad qufmica, basada en la forma en que la biomasa total se distribuye en diferentes compuestos químicos. En la práctica se puede limitar el estudio de la diversidad a una sección limitada de la amplia gama de compuestos químicos. Es probable que las proporciones relativas de grasas, glúcidos, quitina, o de ciertos aminoácidos, en una muestra de plancton, puedan selvir para calcular expresiones equivalentes a una diversidad, con correspondencia notable con las diversidades calculadas sobre la distribución de individuos en especies. Una población muy diversa por este concepto es de suponer que tendría también una mayor diversidad química reflejada de algún modo en índicess fáciles de caloular. 
Para el fitoplancton, los pigmentos sintetizadores constituyen un grupo de compuestos sobre el que es posible calcular indices de diversidad. En las poblaciones poco maduras, en rápido crecimiento, existe una proporción relativamente elevada de clorofila $a$; en poblaciones más maduras, la composición de los pigmentos es mucho más compleja y equilibrada, con proporciones muy importantes de carotinoides. En planctologia se calculaban habitualmente las concentraciones de distintos pigmentos por medio de las expresiones de RicHaRDs \& THOMPSON. Estas expresiones resultan inexactas, dada la variedad de pigmentos y lo fácilmente que se alteran. Sin embargo, el cociente entre las densidades ópticas a 430 y 665 milimicras de un extracto acetónico del fitoplancton $\left(D_{430} / D_{065}\right)$ ofrece una medida conveniente y muy manejable de la diversidad de pigmentos. Es también, desde luego, una cifra relativa; $\mathrm{y}$, lo que es importante, suele mostrar una correspondencia aceptable con la diversidad biótica de las mismas muestras (MARGALEF, $1961 \mathrm{~b}$, correlación entre ambas magnitudes, $+0,4$, con una probabilidad de 1 por mil que sea debida al azar), y también con el flujo de energía por unidad de biomasa (MaRgaLife, $1963 b$, en prensa).

Se tienen motivos para suponer que un índice $D_{430} / D_{665}$ elevado indica un sistema fotosintetizador más estructurado. Las interacciones entre pigmentos (efecto Emerson) permiten comprender cómo una'concentración baja de pigmentos, en condiciones relativamente estables, y con el cociente $D_{430} / D_{005}$ alto, consigue una eficiencia elevada.

El Indice $D_{4 \mathbf{4}} / D_{\text {вв }}$ tiene otra cualidad, que si es indeseable para el fisiólogo, puede ser útil para el ecólogo. Fin todos los extractos de un seston que contiene fitoplancton muerto, algas que han pasado por el tubo digestivo de animales, o animales, dicho índice resulta más elevado, de manera que se exagera el contraste entre el índice de una población madura y el de una población de fitoplancton que crece con gran actividad y sin consumidores. YenTson \& RYTHER (1959) han estudiado los espectros de abisorción de extractos de seston de diversas profundidades; sus datos permiten calcular para $D_{430} / D_{605}$ valores de 2 a 3 en poblaciones vivas naturales, de hasta 4 en poblaciones con el crecimiento limitado por baja concentración de nitrógeno, y hasta de más de 20 en el seston obtenido en el mar entre 500 y 1000 metros de profundidad. Los materiales liberados por algas trituradas (Ascophyllum, YENTSOH \& REIoHERT, 1962) dan extractos cuyo índice $D_{430} / D_{665}$ aumenta a medida que pasa el tiempo. En los espectros presentados por CoRRIE (1962) se manifiesta el consabido aumento del fndice al pasar del fitoplancton fresco a los excrementos de Calanus alimentados con aquél, la variación es del orden de 2,8 a 4,3. En aguas de Barcelona, después de intensas lluvias que provocaron inundaciones $\mathrm{y}$ un acarreo excepcional de materiales de origen terrestre hacia el mar, dicho indice subió anormalmente (hasta 
12-20, fig. 7) en el seston de aguas superficiales que contenian mucho material detritico junto a un fitoplancton normal. Se puede recordar aquí, porque tiene más valor que una simple analogía, que el índice $D_{430} / D_{005}$ aumenta en las algas maduras, que se aprestan a la reproducción. La relación carotinoides/clorofila guarda correlación positiva con el índice $D_{430} / D_{\text {os5 }}$. Aquella relación vale 0,12 en el talo vegetativo de Ulva, 0,29 en los márgenes de talos con gametangios femeninos, y 0,37 en los gametas femeninos; en los bordes del talo con gametangios masculinos vale también 0,37 , y en los mismos gametas masculinos, 0,89 (Haxo \& CLENDENNING, 1953).

La divensidad de pigmentos, expresada por el índice $D_{430} / D_{605}$, se puede medir en una población uniespecífica. Los datos reunidos por el Instituto de Investigaciones Pesqueras permiten asegurar que, a medida que la población envejece, dicho indice aumenta, con regularidad casi general. La calidad de los pigmentos, expresada por dicho índice, depende menos de la calidad de la luz que de la concentración de elementos nutritivos disponibles. Pueden existir, por tanto, medidas de adiversidad», o, mejor dicho, de madurez, aplicables a poblaciones uniespecificas. Al parecer es posible encontrar medidas semejantes de madurez calculables, no sobre pigmentos o sobre otros compuestos químicos, sino sobre los mismos individuos. Por ejemplo, la distribución de los individuos de una población en clases de edad. A la distribución se puede aplicar la consabida fórmula $-\Sigma p_{i} \log _{2} p_{i}$, tomando como vialores de $p_{i}$ las probabilidades que un individuo, sacado al azar, tiene de pertenecer a cada una de las clases de edad que componen la población, lo cual se relaciona, naturalmente, con la curva de mortalidad. Una población con una tasa de mortalidad elevada nos dará un afndice de diversidad" muy bajo, que permite calificar a la población de juvenil o poco madura. Por el contrario, una población con una tasa de mortalidad más baja, con una mayor representación de las clases de edad más viejas, podrá ser calificada de más madura, más diversa en relación con la edad. En buena correspondencia con lo que se dirá en la sección siguiente, una población de tipo juvenil arguye un gran flujo de energía por unidad de biomasa. También puede emplearse como indicio la proporción de individuos muertos (por ejemplo, en poblaciones de rotiferos, Berzins, 1958), manifestación de senilidad en poblaciones muy maduras.

En las poblaciones polimorfas es posible calcular una divensidad sobre las frecuencias de los distintos morfos. Las diferencias morfológicas entre individuos de la misma edad, expresable en dimensiones absolutas y relativas de las distintas partes del cuerpo, ofrecen otra posibilidad de apreciar el grado de diversidad de las poblaciones. Puede resultar interesante hacerlo cuando en el seno de una masa de agia extensa se presenta cierto grado de diferenciación, debido en su mayor parte a las distintas 


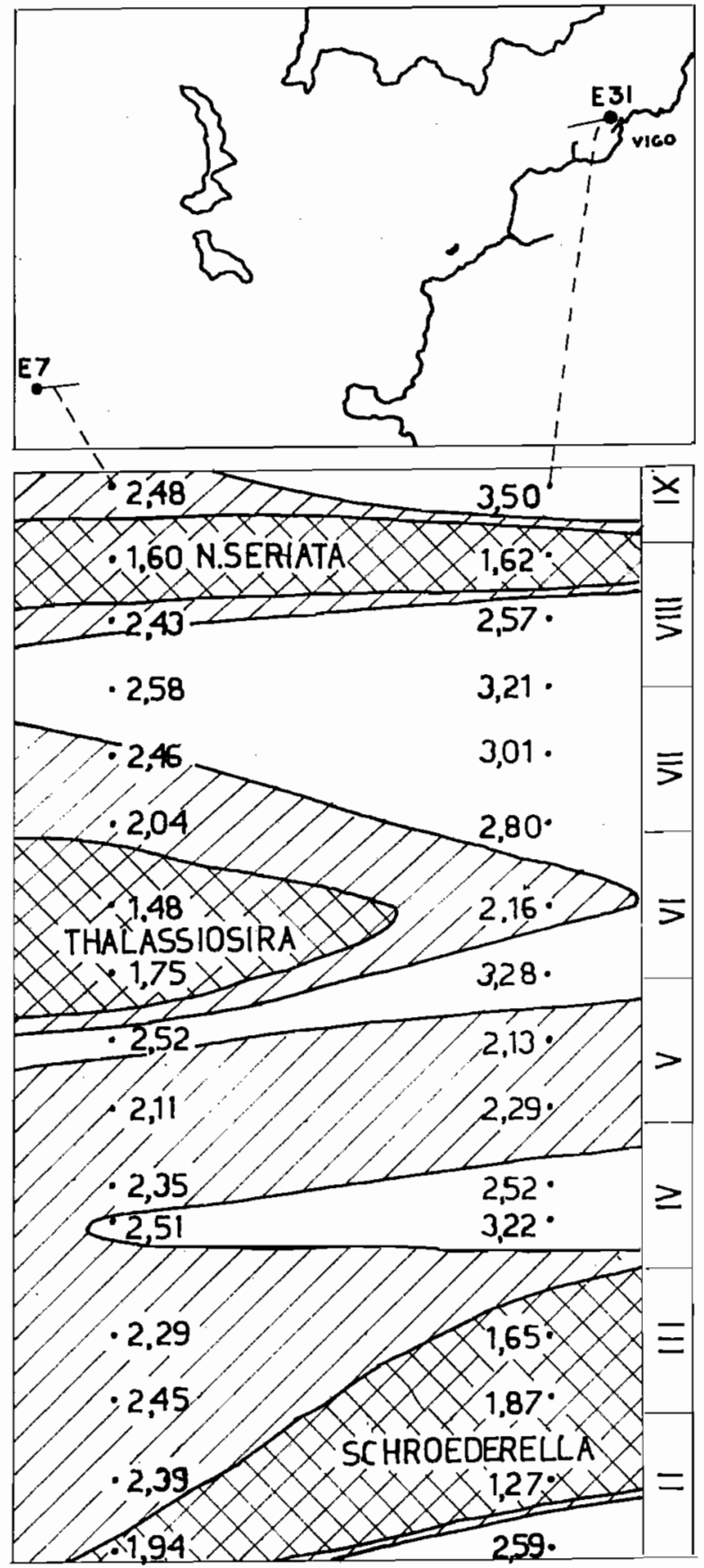

Fra. 5. - Valores del índice de diversidad (en bits por célula) en dos estaciones de la Ría de Vigo (E 7, E 31), de febrero a septiembre de 1962. Los valores han sido calculados sobre muestras obtenidas con red de fitoplaneton por F. Fraga. Los momentos de mínima diversidad corresponden a 1 dominancia de alguna de las especies que se indican : Schroederolla delicatula, Thalassiosira sp. y Nitzschia seriata. 


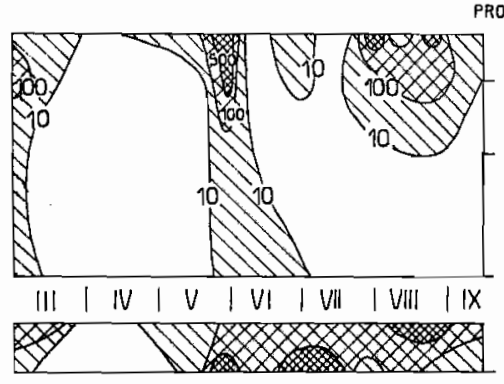

TOTAL CELUULAS

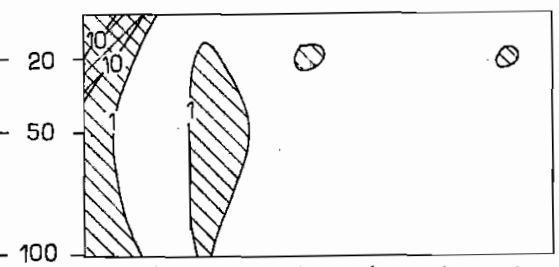

lii | IV I $V$ | VI I VII I VIII ! IX

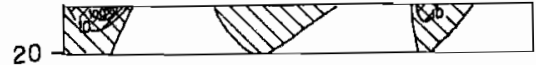

SCHROE DERELLA
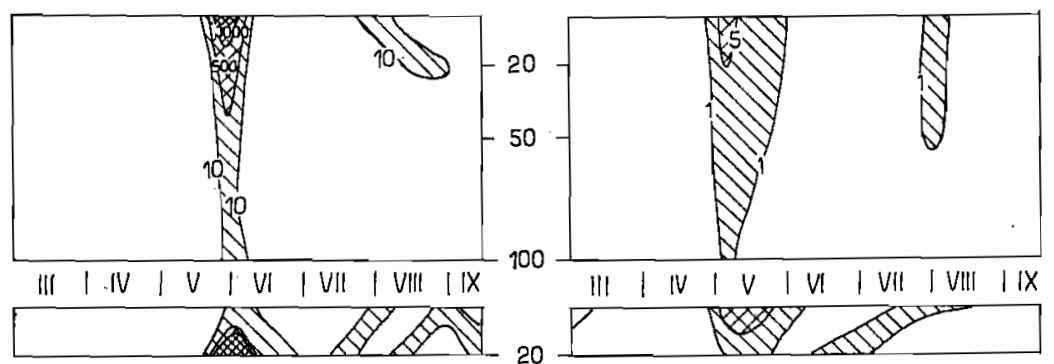

THALASSIOSIRA Y CHAETOCEROS PEQUEÑOS

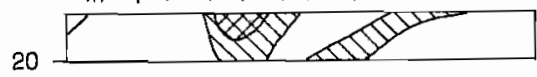

EXUVIAELLA BALTICA

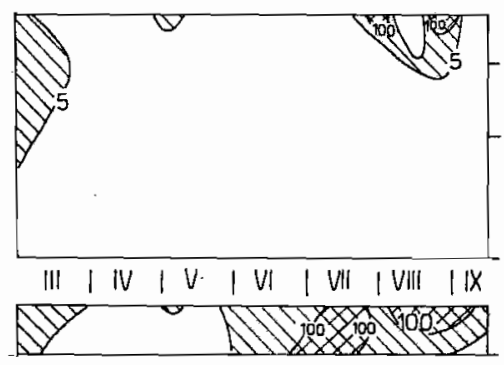

LEPTOCYLINORUS

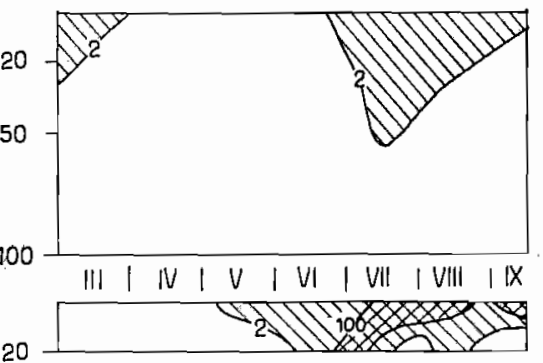

CERA TIUM FURCA

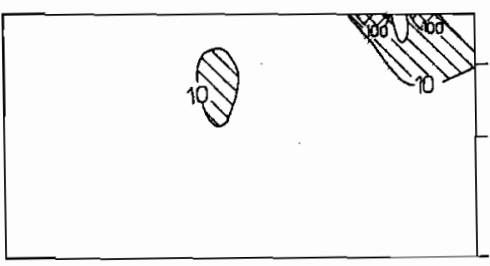

III I IV I V | VI | VII | VIII IIX

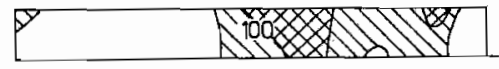

NITZSCHIA DELICATISSIMA + SERIATA

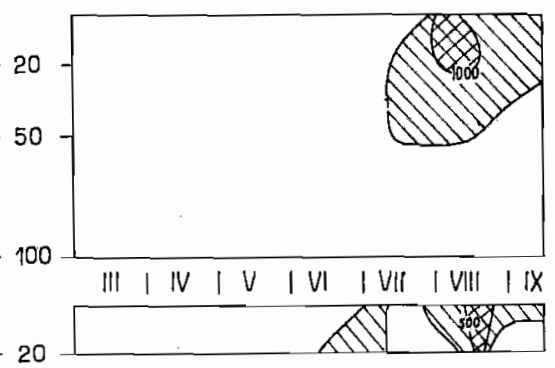

CERATIUM FUSUS

Fig. 6. - Distribución vertical (escalas en metros, en el centro: 0-100, estación $\mathrm{E} 7$; 0-20, estación $\mathbf{E} 31$ ) y temporal (marzo a septiembre de 1962) del total de células y de algunas de las especies más importantes del fitoplaneton en las estaciones E 7 y E 31 (véase su situación en fig. 5) de la Ria de Vigo. Las cólulas han sido contadas en muestras de agua recolectadas por F. FraaA, previa su sedimentación en cúmaras del microscopio de Utermöhl. Las concentraciones se expresan en células por ml, excepto en el caso de las dos especies de Ceratium, cuyas densidades se dan en células por $100 \mathrm{ml}$. 
condiciones de vida a que estuvieron sometidos los individuos durante el crecimiento, pero sin descontar pasibles diferencias genéticas (BALDI y colaboradores ; Berzins, 1958; Margalef, 1955). La dispersión de los valores alrededor de las dimensiones o proporciones medias puede considerarse como una diversidad $y$, en el sentido en que la estamos utilizando, puede relacionarse con el grado de mezcla o turbulencia del agua. Una población uniespecífica se puede considerar como una población ajustada a un isolo nicho ecológico, de manera que la sucesión llevaría a un decrecimiento de la diversidad. Una población muy variable sólo subsistirá en las condiciones que son comparables a las de los jugadores con intereses en distintas mesas de juego del ejemplo usado unas páginas atrás, es decir, en condiciones de cierta movilidad y mezcla, activa o pasiva, de las poblaciones.

Finalmente, conviene indicar que algunos criterios simplificados, por ejemplo, el de clasificar las partículas del seston por sus tamaños (lo que puede hacerse automáticamente con un contador CodLTER u otros similares) o por el tipo de fluorescencia que producen al ser excitadas, pueden proporcionar una indicación aproximada y rapidísima de la complejidad real del ecosistema.

\section{RELACIONES ENTRE FUNCION (FLUJO DE ENERGIA) Y ESTRUCTURA U ORGANIZACION DE LOS ECOSISTEMAS}

Relaciones básicas y modielo teórico. - Diversos estudios sobre fitoplancton nos muestran de una manera empírica ciertas relaciones existentes entre diversidad y productividad. Podemos considerar el ejemplo de la ría de Vigo resumido en las figuras 5 y 6 . En los momentos en que se produce un rápido aumento en la concentración de plancton se manifiesta un descenso de la diversidad. En otros términos, un aumento de la productividad va ligado ordinariamente a la manifestación de dominancia por parte de una o pocas especies. No es ello exclusivo de las comunidades acuáticas; en las terrestres, la relación producción/biomasa decrece paulatinamente con el aumento de la estructura, al pasar de comunidades herbáceas al bosque (WhitTakeR, 1961). En un trabajo anterior (MARGALEF, $1963 b$ ) se han presentado cifras concretas referentes al plancton de embalses de agua dulce, y en la figura 7 se resumen éstas y otras que hablan en el mismo sentido.

Conviene establecer la relación entre flujo de energía (producción primaria/biomasa total) y organización o estructura de una manera más general. Anteriormente (Margalef, 1962 b), siguiendo a Pringle y a BRAY, reconocí que la organización no se puede representar por la simple diversidad - cualquiera que sea el plano en que se la mida-, sino 
que depende también de su grado de persistencia en el tiempo. La justificación teórica de la correspondencia fundamental se debe buscar en la cibernética : un sistema más organizado, con un número elevado de posibles relaciones entre sus elementos (relaciones que se extiendan sobre el tiempo), tiene mayor capacidad de autorregulación, más estabilidad y puede subsistir con menor aportación relativa de energía que un sistema más pobremente organizado. Pero la capacidad y rapidez de regeneración o reconstrucción es mayor en un sistema donde el flujo relativo de energía es alto, es decir, corresponde a un grado menor de organización.

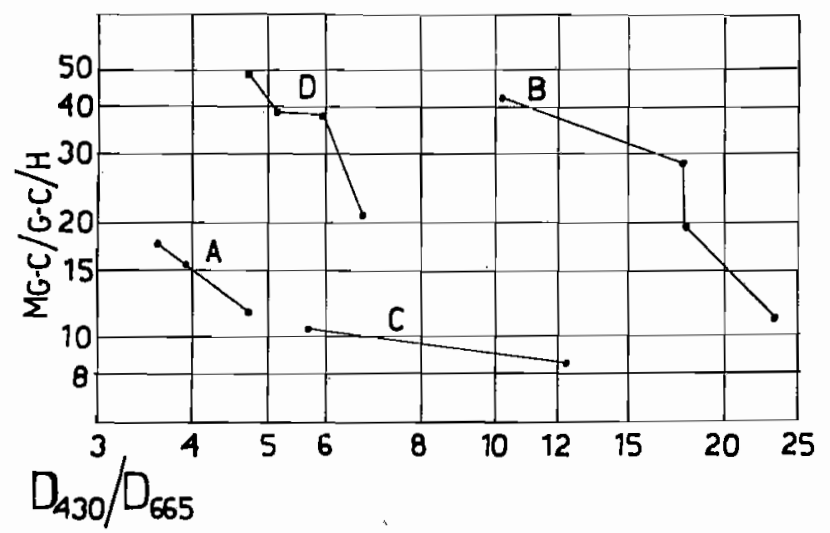

Fra. 7. - Relaciones entre flujo de energla por unidad de biomasa y diversidad de pigmentos. El primero se expresa en ordenadas, en mg de carbono asimilado por hora por cada g de C orgánico presente. El segundo, en abscisas, por el cociente entre las densidades ópticas a 430 y 665 milimicras del extracto del plancton en acetona. $A$, población de Amphidinium en cultivos de laboratorio. $B$, plancton de aguas superficiales del Mediterráneo en las proximidades de Barcelona, octubre de 1962; los valores del cociente $D_{430} / D_{005}$ son anormalmente altos por causa de una abundante mezcla de material detrítico de procedencia continental. $C$, planeton de aguas superficiales del Mediterráneo cerce de Castellón, julio de 1962. $D$, plancton de agua dulce, en varios embalses de Cataluña, julio de 1962.

Se puede intentar dar expresión matemática a estas relaciones. Sea

$P=$ producción, energía que fluye efectivamente a través del sistema organizado, por unidad de tiempo. Prácticamente equivale a producción primaria.

$B=$ biomasa. Soporte material de la organización ; con el mismo sentido deberían incluirse también porciones no vivas (pedúnculos de algas fijas, ma.dera en los bosques, etc.) por cuanto contribuyen a mantener la estructura de la comunidad. 
$C=$ energía contenida por unidad de biomasa. Pocos autores se han ocupado de este concepto desde el punto de vista de la ecología general (Slobodkin, 1961). Según otra manera de entender la fórmula, $C$ podría asimilarse a la ecofuerza de H. T. ODum (1960).

$D=$ complejidad, apreciada por la diversidad a nivel de la distribución de individuos en especies o a nivel de los pigmentos.

$d=$ tasa de degradación de la complejidad con el paso del tiempo.

Las relaciones básicas se pueden expresar probablemente de la siguiente forma, para un tiempo unidad :

$$
\frac{P}{B}=\frac{C}{D e^{-d}}
$$

$P / B$ corresponde al flujo de energía por unidad de biomasa y tiempo, que está inversamente relacionado con el tiempo de renovación o de residencia (aturnover», «residence time»). Ordinariamente, aunque no siempre, los valores de $D$ y $d$ muestran correlación inversa : un sistema más complejo suele estar expuesto a una degradación menor. Cuandb la complejidad es uartificial», como la que resulta de la mezcla de poblat ciones de composición diferente en la frontera entre dos masas de agaa de características distintas, $d$ será también elevado. Si consideramos la misma expresión sobre un periodo de tiempo considerable, $t$, tendríamos

$$
\frac{P t}{B}=\frac{C}{D e^{-d t}}
$$

Entonces, para que $d$ permanezca constante, si $P / B$ no varía, tiene que aumentar $D$. Si $P$ es constante, $B$ y $D$ han de mostrar correlación positiva. Cuando la energía fluye por un camino más complejo, salvando una serie de desniveles menores, una misma energía puede mantener una mayor biomasa. Con una misma biomasa, un contenido calórico medio mayor puede ser asiento de una mayor organización. Un enorme flujo de energía a través del sistema corresponde a una violenta desorganización del mismo.

La expresión indicada cumple con éstas y otras condiciones que deben pedirse a cualquier representación idealizada de propiedades sintéticas de los ecosistemas. Las dimensiones físicas de las magnitudes que en ella figuran son coherentes :

$$
\frac{M L^{2} T^{-3}}{M}=\frac{L^{2} T^{-2}}{T}
$$

recordando que $D$, en términos de información, carece de dimensiones. 
Estados de tensión y fluctuaciones. - Puede ser útil escribir la expresión anterior en la siguiente forma:

$$
P=\left[B / e^{-t}\right] \cdot[C / D]
$$

En el primer miembro, $P$ se relaciona con las propiedades del ambiente y puede definirse un valor $P^{\prime}$ que corresponderá al flujo de energía posible en aquellas condiciones dadas, función de la intensidad de la luz, concentración de elementos nutritivos, turbulencia, etc. :

$$
P^{\prime}=f(I, F, N, T \ldots)
$$

La diferencia $P^{\prime}-P$ es muy importante en la dinámica de los ecosistemas, pues en tanto dicha diferencia no se amula, la comunidad permanece en cierto estado de tensión. Aun en el caso en que dicha diferencia sea cero, la comunidad puede reestructurarse, aumentando $B$ y $D$ y disminuyendo $d$. Si $C$ también aumenta, entonces el incremento de organización puede ser aún mayor. De todos modos, cualquier diferencia entre $P^{\prime}$ y $P$ representa una "fuerzan aplicada a la comunidad, un factor de cambio.

En el segundo miembro se han reunido las magnitudes que se refieren a características de la comunidad, agrupadas en forma de dos factores. $\left[B / e^{-d}\right]$ incluye las variantes que responden rápidamente. Cualquier cambio ambiental puede representarse por la diferencia $P^{\prime}-P$. Tanto si es positiva como negativa, la biomasa y la tasa de degradación de la diversidad se alteran inmediatamente.

$[C / D]$ incluye variantes que se modifican lentamente en la comanidad, pues requieren la sustitución de unas especies por otras o la manifestación de un proceso histórico de adquisición o pérdida de la diversidad, dependiente de la interacción entre muchas especies a lo largo do cierto tiempo.

En otros términos, toda comunidad se adapta al flujo de energía posible $P^{\prime}$. La adaptación se produce de manera que la demora es mayor en $[C / D]$ que en $\left[B / e^{-\tau}\right]$.

La utilización plena de las posibilidades de producción se tiene cuando la demora es nula, como se puede deducir con claridad cuando se consideran fluctuaciones periódicas de $P^{\prime}$. Pero si el retraso de $B$ o de $D$ es superior a medio ciclo (onganismos de vida larga), la comunidad ha superado los ciclos y su estabilidad es grande.

En relación con los ciclos, tienen importancia los mecanismos anticipadores, respuestas de los organismos a determinados factores, o ritmos internos, que por si carecen de significado ecológico, pero que los ponen en condiciones de aprovechar ciertas oportunidades de aumentar la producción, desde el momento en que éstas aparecen. En este sentido 
debe interpretarse la dependencia de los pigmentos del fitoplancton, mayor respecto a la concentración de elementos nutritivos que respecto a la luz. La luz retorna con regularidad según un ritmo corto (diario), y su mayor aprovechamiento requiere que la adaptación a la misma sea anticipada. Además, esta adaptación sería inútil de no existir concentración suficiente de elementos nutritivos en el medio. Se comprende, por tanto, que en el curso de la evolución, la cantidad y calidad de los pigmentos hayan llegado a estar reguladas por la concentración de elementos nutritivos en el medio y por ritmos internos.

Intercambio entre ecosistemas vecinos de distinta madurez. - En la frontera que los separa se manifestaré la difusión de los elementos de las respectivas comunidades en sentidos opuestos, produciéndose una mezcla de elementos de las dos, tanto más amplia cuanto mayor sea la turbulencia. Esta población mezclada puede servir de base a una selección, o punto de partida a una sucesión futura; es una situación irreversible, una decisión (LANDAUER, 1961). Si acontece que las dos poblaciones mixtas en contacto corresponden a dos masas de agua de característicás físicas diferentes que se aproximan a lo largo de una superficie de discontinuidad y con fácil deslizamiento de una sobre otra (picnoclinas o frentes marinos), puede ocurrir que ambas masas sean complementarias en 'iertos elementos nutritivos, inorgánicos (una más rica en $\mathrm{P}$, la otra en $\mathrm{N}$ ) u orgánicos. Un contacto de este tipo puede llamarse activo, porque aumenta bruscamente el flujo potencial de energía y la comunidad fronteriza adquiere caracteres propios y de menor madurez. Si la mezcla de las dos masas de agua no aumenta el flujo potencial de energia, el contacto puede llamarse pasivo y se limita a una mezcla e intercambio de elementos entre los dos ecosistemas o las dos partes del ecosistema. Bajo la influencia de este intercambio, la diversidad puede aumentar más en el subsistema menos maduro que en el más maduro; en cambio, la parte de la producción del sistema menos maduro que va a parar y es utilizada en el más maduro, es mayor que el flujo de energía potencial que va en sentido contrario. En el mar, siempre hay un transporte de energia de las manchas de agua más turbulenta a las manchas menos turbulentas, y de las aguas superficiales a las profundas.

En todos los casos, una población que se expande en el seno de una masa de agua disminuye su madurez (la madurez se hace proporcional a $B / P$ o a $\left.D e^{-d} / C\right)$. Tal difusión sólo puede mantenerse si $P / B$ es alto y si la población que se expande es consumida o sedimentada en otro punto. Por el contrario, la contracción de una población, asociada siempre a un movimiento activo de sus componentes, corresponde a un incremento de las características de madurez. 


\section{LAS aMANCHAS»DE PLANCTON Y CONDICIONES PARA SU PERSISTENCIA}

aManchas de plancton. - Al referirse a la distribución no uniforme del plancton en el espacio, los autores suelen hablar de manchas («patchesn), que se pueden definir como volúmenes de agua en los que la densidad de determinada especie, o de un conjunto de especies, rebasa cierto valor (BAINBRIDGe, 1957 ; CUsHing, 1962). Tácitamente parece que consideran a semejantes manchas como unidades de estructura, o por lo menos como entidades que permiten un tratamiento cualitativo. Pero, en realidad, las manchas de plancton no están mejor definidas que las «asociaciones» vegetales y son mucho más fugaces. Desde el punto de vista de una teoría ecológica general, una mancha de Rhizosolenja tiene un significado completamente distinto de una mancha de Calanus. El concepto estricto de mancha de plancton tiene poco interés desde el punto de vista del presente artículo. Las distribuciones elementales ilustradas en las figuras 1 a 3 pueden considerarse como manchas de plancton. Son simples elementos para edificar modelos más complejos. Ahora interesan las estructuras resultantes de la suma de distribuciones de distintas especies. Cada distribución uniespecifica puede tener forma de mancha 0 no merecer este nombre.

Difusión. - Una condición para la aparición y persistencia de una mancha de plancton es cierta limitación en la intensidad de mezcla de las aguas, o difusión. Existe una considerable literatura sobre la difusión, sea estudiándola teóricamente, sea basada en observaciones sobre la difusión de colorantes, sustancias radiactivas, salinidad (acore methodn), contaminantes (bacterias fecales) o flotadores. Véase Pearson y colaboradores, 1956 ; Moon \& al., 1957 ; Ragotzkie \& PoMERoy, 1957 ; Joseph \& SANDNER, 1958; BodRret \& BroIdA, 1960 ; OzMIDov, 1960 ; Joser 1960 ; Colebroor, 1960 ; UUsitalo, 1961 ; Bowden, 1962 ; RILEY, 1942, 1951.

La densidad o concentración $(N)$ de una sustancia u organismo que se difunde a partir de un centro o punto de origen, al cabo de un tiempo $t$ y en una distancia $x$, viene dada por la siguiente ecuación, que se refiere a una mancha que se extiende según las dos dimensiones horizontales y en el supuesto de una turbulencia $(A)$ constante en todo el campo :

$$
N_{(x, t)}=\frac{N_{0}}{4 \pi A t} e^{-x^{2} / 4 \lambda t}
$$

Si la turbulencia aumenta a medida que nos apartamos del centro de la mancha, en primera aproximación podemos hacerla proporcional a $x$, 
y un factor de proporcionalidad puede ser la velocidad con que se mueven los organismos. Con referencia al centro die la mancha, los organismos se mueven tanto más aprisa cuanto más alejados del centro están ; lo mismo que las galaxias lejanas. Si $A=V x$, tenemos:

$$
N_{(x, t)}=\frac{N_{0}}{2 \pi(V t)^{2}} e^{-x / v t}
$$

Si prescindimos del tiempo, en estado de equilibrio, tenemos

$$
N_{(x)}=N e^{-I c x}
$$

que representa una distribución exponencial negativa a partir del centro de difusión o de multiplicación, como la comentada en páginas anteriores.

En lugar de estudiar concentraciones o densidades de células o de sustancias químicas, se pueden mediar las variaciones en la distancia media que separa cada individuo del que tiene más vecino. El empleo de distancias es útil en comunidades fijas (Clark \& Evans, 1954, etc.) y es muy apropiado para el estudio de la difusión en organismos del neuston (Velella), flotadores, etc. (Rictardoson, 1952 ; OLson, 1953; 1959 ; Bodrret, 1960 ; TchiYe \& OLson, 1960). Véase también Brockiaw (1959). Si la distancia de cada elemento a su vecino más próximo pasá de $l_{0}$ a $l$ en el tiempo $t$, se tiene

$$
F\left[\frac{1}{2}\left(\overline{l-l_{0}}\right)\right]=\overline{\left(l-l_{0}\right)^{2}} / 2 t
$$

en que la línea sobrepuesta significa valores medios de la expresión que cubre.

$F$ es la difusividad de vecindad («neigbor diffusivity») y empíricamente se encuentra que vàle la potencia $4 / 3$ de la separación de las partículas, entre límites de 10 a $10^{8} \mathrm{~cm}$.

$\overline{\left(l-l_{0}\right)^{2}}$ es una medida de la regularidad con que se verifica el proceso de expansión de una población. En una población más organizada esta variancia ha de ser menor. También podemos fijarnos en la contracción de una población - por ejemplo, de animales que se agrupan- y aplicar una formulación semejante. Fn este caso parece probable que $\overline{\left(l \longrightarrow l_{0}\right)^{2}}$ sea siempre menor que cuando la población se expande, aunque faltan datos suficientes para probarlo.

Las expresiones relativas a la difusión pueden aplicarse al estudio de manchas de plancton que se originan por dispersión de individuos a partir de un área que puede considerarse puntiforme, como es la difusión de huevos alrededor de un área o punto de puesta (Cassie, 1959) y hasta a ciertos tipos de agregación social (VOLLENWEIDER, 1956; NISHIZAwA, 1954). Muchas situaciones reales presentan complicaciones. Los coeficientes de difusión pueden variar según una u otra dimensión, 
como ocurre en el seno de una corriente marina. El modelo matemático tiene el defecto de que la distribución se extiende inmediatamente hasta el infinito, mientras que, en realidad, las manchas que se difunden tienen un borde externo idefinible, que avanza y que se encuentra a una distancia limitada.

Sin embargo, las expresiones anteriores se pueden aplicar al estudio del plancton. Aceptando ciertos valores de difusión y un número total determinado de individuos, se puede calcular, para tiempos sucesivos, la fracción de dicho número que seguirán estando encerrados on el interior de una mancha de radio definido. Cus.HIng (1962 b) ha aplicado este modelo al estudio de manchas de Calanus, con resultados realmente interesantes.

Condiciones de equilibrio cuando existe reproducción. - El inconveniente principal del modelo anterior es que sólo es aplicable al estudio de una mancha en un período de tiempo lo suficientemente breve, en relación con la biología del organismo en cuestión, para que no se haya modificado sensiblemente su número como consecuencia de la reproduc-: ción y de la mortalidad. En el último ejemplo de CusHing, relativo a manchas de Calanus, si bajo ciertas condiciones de difusión calculamos las densidades sucesivas decrecientes de una población dentro de un cilindro de radio determinado, podemos calcular también la tasa de multiplicación necesaria para que la población conserve el equilibrio, es decir, para que su densidad total dentro del cilindro no varie. O las condiciones necesarias para un crecimiento de la población dentro de un radio fijo, a pesar de las pérdidas causadas por la difusión de parte de sus elementọs en la periferia. KiERSTEAD y SLOBodKIN (1953) establecen, de manera general, que la dimensión mínima de una mancha de plancton, para que conserve su carácter sin difundirse en el medio circundante, es proporcional a la raíz cuadrada de la difusividad $(A)$ partida por la tasa de multiplicación $(r)$ :

$$
L=C \sqrt{A / r}
$$

Esta expresión ha sido aplicada en dos dimensiones, y el valor del coeficiente $C$ depende de la forma a considerar. Es diferente para un canal con los extremos abiertos que para una mancha circular.

Un problema diferente, pero que conduce a examinar otros aspectos de la persistencia de una manoha de plancton, es el tratado por GRAN y BraARTd (1935), SverdROP (1953) y otros autores posteriores (EnomoTo, 1959 ; Coshing, $1962 a$ ). En la capa superficial en los océanos, de características químicas uniformes y en mezcla constante, el fitoplancton podrá mantenerse en equilibrio o aumentar si la intensidad media de luz que recibe todo el espesor de la capa superficial de mezcla es igual a la 
iluminación en la profundidad de compensación. Si la intensidad media de luz es inferior, la capa suficientemente iluminada experimentará una continua pérdida por difusión hacia niveles menos iluminados. En el planteo del problema se hace $r=f(I)$, siendo $I$ la iluminación. Si $I_{0}$ es la iluminación en superficie, $I_{c}$ la iluminación en la profundidad de compensación, y $k$ el coeficiente de extinción de la luz, la profundidad crítica de la capa de mezcla $D$ viene dada por

$$
I_{c}=\frac{I_{0}}{k D}\left(1-e^{-k D}\right) \quad \frac{D}{1-e^{-k D D}}=\frac{I_{0}}{k I_{c}}
$$

Casos de este tipo introducen nuevos puntos de vista en la discusión del significado de la estructura en sentido vertical. En el precedente ejemplo se deslinda una capa superior de mezcla continua, cuya iluminación media basta o no basta para el crecimiento del plancton y otra capa inferior que se considera aislada. Pero la pérdida de células del fitoplancton es en parte independiente de la mezcla y difusión. En realidad la pérdida de células en las capas superiores se debe principalmênte a una sedimentación pasiva. El problema de la sedimentación pasiva nos enfrenta con un nuevo aspecto de los problemas de la planctología. Hasta ahora considerábamos que la difusión de las células iba unida a la difasión del líquido, es decir, las células podían equipararse a los iones disueltos. Pero en los fenómenos de sedimentación pasiva del plancton, lo mismo que en los de ascensión o agregación activa del fitoplancton y del zooplancton, existe un movimiento relativo de los organismos, diferente de los movimientos de difusión indicados por las moléculas de un colorante o los átomos de un trazador radiactivo presentes en el Iíquido.

Aparece asf́ una nueva condición de equilibrio, manifiesta especia1mente en las manchas de fitoplancton: el movimiento vertical de los organismos, a una velocidad $V$, relativa a las moléculas del líquido. Como es natural, el cambio instantáneo en la densidad de células a un nivel definido depende del gradiente vertical de densidades en dicho nivel; si la densidad es constante, el movimiento vertical y a velocidad uniforme de las células no modifica la densidad. Si $V$ es la velocidad resultante de sedimentación tendremos, siendo $z$ positivo hacia a'bajo :

$$
d N / d t=r N-V \frac{d N}{d z}+A_{\varepsilon} \frac{d^{2} N}{d z^{2}}
$$

que es la expresión usada por Rifiey, Stommer \& Bumpds (1949). Esta expresión se presta a varias deducciones de interés. $V^{2}$ no puede ser mayor de $4 A r$ y en ausencia total de turbulencia ninguna población podría mantenerse por pequeño que fuera $V$. Iguales resultados da la aplica- 
ción de modelos estocásticos de poblaciones, considerando las probabilidades de extinción en distịntas condiciones de multiplicación, sedimentación y turbulencia. Este punto particular tiene interés en la biología de las aguas corrientes, donde la persistencia de potamoplancton requiere que el flujo no sea laminar. También da razón de la dominancia de organismos con diferentes características biológicas en condiciones distintas de turbulencia. La turbulencia acelera la asimilación al disminuir los gradientes en la concentración de elementos nutritivos en la periferia de las algas (MUNK \& RILex, 1952), $r$ es pues función de $A$. La existencia de un movimiento activo ( $V$ negativo) presupone un consumo de energía y sólo es eficaz si la turbulencia tiene valores pequeños. Por otra parte, el valor de la turbulencia se suele relacionar con el espesor de la capa superficial de mezcla y con las limitaciones que ella establece al desarrollo del plancton. Se comprende que diatomeas y dinoflageladas, organismos con propiedades bastante diferentes, predominen alternativamente según las condiciones de turbulencia reinantes.

EI modelo anterior resulta todavía incompleto. Debe introducirse un término más para expresar el consumo de las algas por parte de los ani-: males, otros términos para expresar que la velocidad vertical no es uniforme, sino que experimenta aceleraciones o retardos, al pasar los organismos por ciertos niveles (MargaLer, 1963a). Añádase la difusión y turbulencia en sentido horizontal, que puede ser diferente según las direcciones. La difusividad turbulenta es mucho mayor en sentido horizontal que según la dirección vertical y existen diferencias grandes según los niveles (RILEY, 1951). Alcanza valores particularmente elevados en las picnoclinas o superficies de discontinuidad, a cuyo nivel puede observarse una expansión lenticular de las manchas de plancton. Por otra parte, tanto la sedimentación como los movimientos activos se apartan poco de la vertical, lo cual representa una simplificación; pero las trayectorias ascendentes, al llegar a una superficie de discontinuidad fisicoquímica, y en especial a la superficie del líquido han de anular o invertir su velocidad, presentándose acumulaciones que escapan a una formulación sencilla. Finalmente, las situaciones se complican por la interacción entre los movimientos del medio y de los organismos. Si tenemos dinoflageladas fototácticas en una masa de líquido, los organismos se concentran en aquellos puntos en que la velocidad horizontal disminuye y la vertical aumenta, hasta cierto punto ; pero se dispersan donde la velocidad horizontal aumenta y la vertical disminuye. Estos organismos se oponen activamente al arrastre vertical, pero se dejan arrastrar pasivamente por los movimientos horizontales (COLEBRooK, 1960 ; RAGOTZKIE \& BRYSON, 1955).

En resumen, cualquier distribución de individuos en el espacio que se considere como una «manchan de plancton, tiende a adquirir una con- 
figuración más probable y una energía libre minima. La población tiende a la máxima dispersión y uniformidad y, si las células son más densas que el agua, a una sedimentación total. El mantenimiento de una (mancha» de plancton en estado aproximado de equilibrio requiere la actuación de fuerzas que se opongan a las que conducen a la situación de máxima entropla : la multiplicación de los organismos y los movimientos activos de los mismos. La persistencia de la amanchan de plancton como estructura espacial requiere que la producción de nuevos organismos sea más intensa o haya sido más intensa en un volumen limitado del agua. Por otra parte debemos acostumbrarnos a deslindar total o parcialmente los movimientos de los organismos y los movimientos de la masa de agua.

\section{SISTEMAS CON UN FOCO ŨNICO DE MINIMA O MÁXIMA MADUREZ}

Sistemas de manchas de plancton. - Apenas puede imaginàrse la complicación a que nos llevaría el estudio simultáneo de muchas amanchasy de plancton, no coincidentes en el espacio y formadas por muchas especies, a cada una de las cuales tratáramos de aplicar las nociones de tasa de multiplicación, de consumo, de difusión vertical y horizontal, de velocidad de sedimentación o de ascensión, de aceleraciones o retardos en los movimientos de las células u organismos al atravesar determinadas capas, etc. El estudio qnizá se simplifica si nos limitamos a describir los rasgos principales, y utilizamos algunas generalizaciones, como, por ejemplo, que las manchas son mucho mejor delimitadas cuando las tasas de multiplicación son elevadas y las dle difusión bajas, que las diatomeas y las dinoflageladas resultan favorecidas, respectivamente, en aguas turbulentas y en aguas más estabilizadas y que existen ciertamente interacciones biológicas que dan razón de algunas caracteristicas de las manchas. Así, el fitoplancton sólo se puede acumular en gran cantidad cuando escasean los animales consumidores; la migración vertical da a los animales una mayor movilidad respecto a los vegetales; cuando el agua está estratificada, regulan liasta cierto punto la asociación de "manchasn de zooplancton y de "manchas» de fitoplancton, habiéndose supuesto cierta tlendencia a la exclusión (HARDY, 1952). Sin embargo, en la presente discusión nos interesa tratar el problema de manera más sintética y completa.

Centros de minima madurez. - Se han de caracterizar por un mayor flujo de energía y por una menor organización. Se originan por una alteración de las condiciones del medio o por una intervención violenta sobre 
Ia comunidad - un claro en el bosque es un ejemplo típico de centro de mínima madurez- y su evolución normal es hacia un aumento de la madurez. Para que puedan persistir como tales centros de minima madurez, por más tiempo del que corresponde a la sucesión normal in situ, ha de existir un intercambio con las comunidades periféricas más maduras. Este intercambio ha de representar fundamentalmente una exportación de energía del centro menos maduro a la periferia más madura o, dicho en otros términos, a una explotación del centro por la periferia. Dicha explotación puede ser pasiva. Frecuentemente un centro de mínima madurez se caracteriza por una gran biomasa y una enorme producción —coincide con una amancha» formada por una o por pocas especies dominantes- $-\mathrm{y}$ entonces la simple difusión da razón de la exportación. O bien se trata del plancton de aguas superficiales, sometido a sedimentación continua de parte de sus elementos. En otras ocasiones, animales de otras comunidades ejercen una explotación activa, como cuando los animales filtradores del bentos se alimentan del plancton.

Debe decirse expresamente que aun cuando un centro de mínima madurez puede coincidir frecuentemente con una «manchan de determinada especie, dicha coincidencia no es necesaria y teóricamente los centros o nodos de mínima madurez podrían estar sembrados sobre una compleja población mixta, desconectados de la distribución de las especies consideradas aisladamente. Un centro de mínima madurez es, simplemente, una herida en activa regeneración en el complicado tapiz que teje en el espacio la distribución de numerosas poblaciones uniespecificas.

Estructuras hidrográficas asociadas con los centros de minima madurez. - Fundamentalmente han de ofrecer posibilidades de producción no utilizadas y ordinariamente se caracterizan, además, por cierto grado de variabilidad o fluctuaciones en los distintos factores, unida a una difusión o dispersión que contribuye a la exportación de una parte de la biomasa. Pueden tener las siguientes formas :

1) Aportación continua en un lugar muy definido de un agente de producción, que permite el desarrollo de una abundante población mixta que se dispersa a partir de dicho punto, donde existe siempre un elevado flujo de energía por unidad de biomasa. Ejemplo : influencia de vertidos ricos en $P, N$, como los estudiados en el puerto de Barcelona, en relación con la biología de áreas inmediatas. El fitoplancton de las aguas inmediatas al puerto muestra las características de menor madurez: menor diversidad biótica, índice $D_{430} / D_{6,65}$ más bajo, cociente producción/biomasa más alto.

2) Una masa de agua se traslada hasta encontrarse en condiciones que permiten aumentar rápidamente la producción primaria. EI caso 

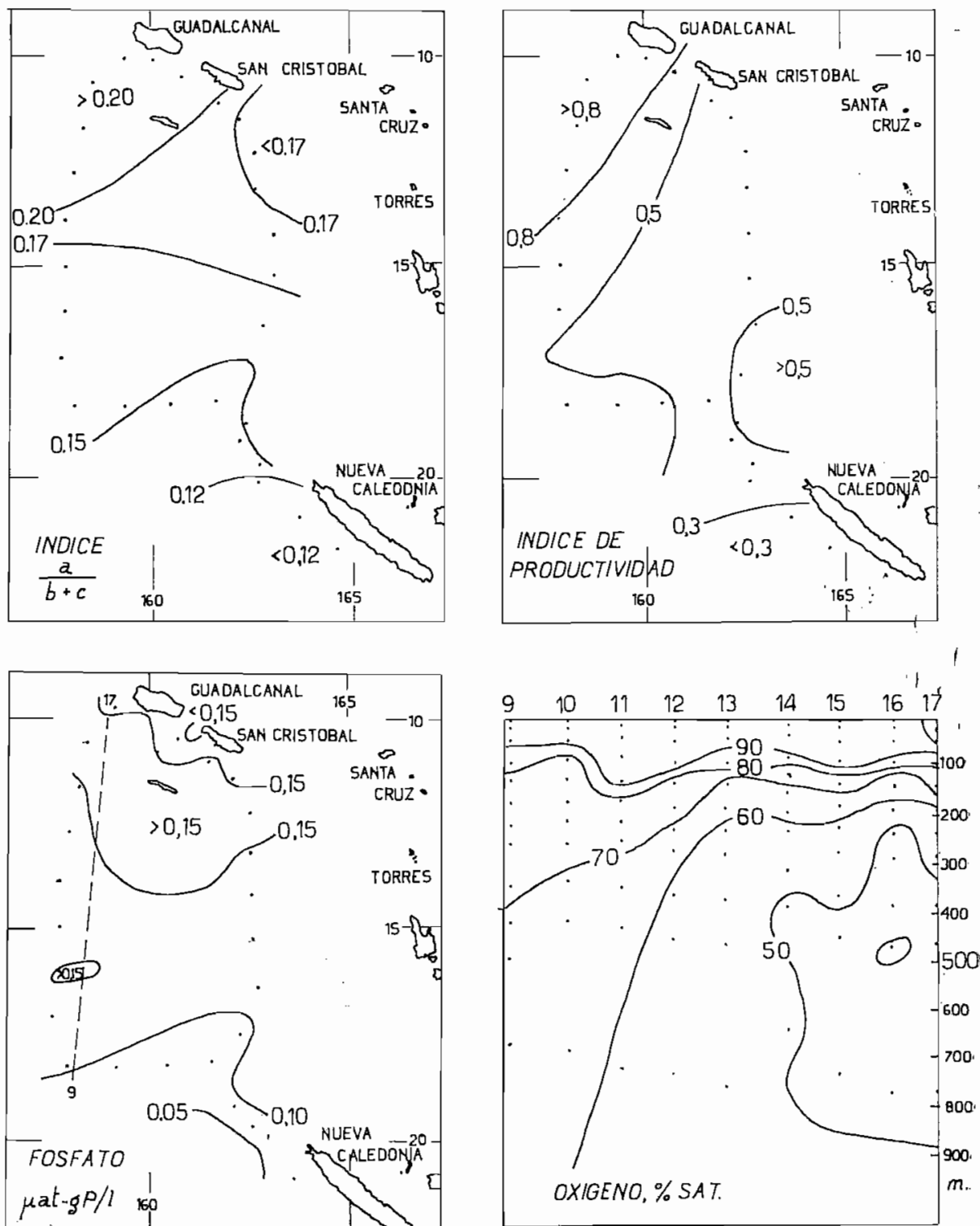

FIa. 8. - Algunas caracteristicas del fitoplancton y del ambiente en un área del Paclfico tropical durante el mes de septiembre de 1960, según datos de WAUTHY y Rotschr (1961). Superior izquierda, fndice clorofila a y $b$ expresadas en $\mathrm{mg}$, clorofila $c$ en unidades MSPU) del plancton obtenido en aguas superficiales; este indice muestra correlación inversa con el indice $D_{430} / D_{005}$. Superior derecha, Indice de productividad estimado con aproximación; el indice de productividad (sensu STRIOKLAND) es la producción primaria neta por hora por $\mathrm{mg}$ de $\mathrm{C}$ 
más normal es la ascensión de aguas profundas hacia niveles iluminados. Todas las formas de afloramiento son centros de mínima madurez. Los estudios en Castellón han puesto de manifiesto una disminución de la diversidad biótica y un descenso del índice $D_{430} / D_{665}$ en todos los casos en que existe mezcla vertical o afloramiento (HERRERA \& MARGALEF, diver'sos trabajos). La disminución de la madurez así manifiesta es mayor donde y cuando dichos procesos son más intensos.

3) El movimiento de los organismos en relación con el agua establece condiciones de menor o mayor madurez. En todos los puntos de dispersión o sedimentación de los organismos, activa o pasiva, las distintas características sintéticas de las poblaciones (diversidad biótica, índice $D_{430} / D_{005}$, producción por unidad de biomasa presente), coinciden en indicar una menor madurez en el sentido en que ésta se definió. El caso más general es la menor madurez del plancton de superficie en relación con el plancton de profundidad y el gradiente de madurez es tanto más intenso cuanto más activa es la sedimentación (en primavera, por ejemplo, con una intensa sedimentación de diatomeas) (cf. MARGALEF \& Herrera, 1963; Ferrera \& Margalef, 1963). Se pueden añadir: como casos particulares los de explotación activa.

Las dimensiones de las estructuras hidrográficas que son sede de centros de mínima madurez son muy variables. En los estudios ordinarios de oceanografía y reflejándose en los mapas de topografía dinámica, se reconocen torbellinos desde unas 10 millas de diámetro hasta dimensiones muy superiores. Los torbellinos ciclónicos o ascendentes, o divergencias, son siempre asiento de poblaciones menos maduras. SARGENT \& WALKER (1949) encuentran en los centros de las divergencias abundantes poblaciones de Chaetoceros socialis, Chaetoceros compressus, etc., todas ellas especies características de comunidades poco maduras, mientras que en la periferia son comunes las Rhizosolenia, indicadores de situaciones algo más maduras. Véanse también los datos de Doтr \& OgURI (1958). Rotschy y WaUtHy (1961) muestran un excelente ejemplo estudiado en el Pacífico (fig. 8). LaEvastu (1962) discute la probable distribución del fitoplancton y del zooplancton en relación con torbelli-

del fitoplancton bajo una intensidad luminosa de un $1 \mathrm{y} / \mathrm{min}\left(=1 / \mathrm{gcal} / \mathrm{cm}^{2} / \mathrm{min}\right)$. En este caso la biomasa ha sido calculada a partir de la concentración de pigmentos ₹ la productividad extrapolada a $1 \mathrm{ly} / \mathrm{min}$. Inferior izquierda, distribución superficial del fosfato inorgánico. Inferior derecha, distribución de los valores de saturación de oxlgeno en profundidad y a lo largo de una sección que va de las estaciones 9 a 17, según la linea de trazos del mapa inferior izquierda. Al NW de la zona estudiada existe un área de máxima producción, mínima diversidad de pigmentos y posiblemente de mínima diversidad biótica, a juzgar por listas de la composición del fitoplancton en estos mismos parajes $y$ en fechas anteriores, publicadas por los mismos autores. La distribución del oxlgeno hace ver que dicha área es también lugar de exportación de materia orgánica, que es respirada en volúmenes de agua adyacentes, especialmente en profundidad. 

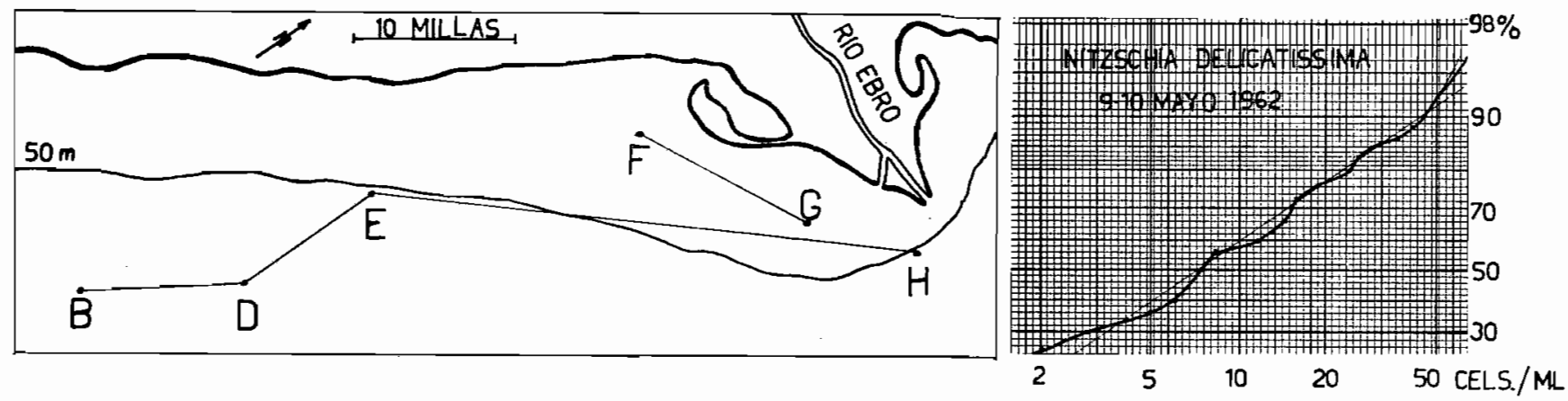

Fig. 9. - Mapa de la región del sur de la desembocadura del Ebro, a la que hacen referencia las figuras 10, 11, 12, 13 y 14, con indicación de las estaciones consideradas. La estación $A$ se halla a media distancia entre la $B$ y la costa más cercana. A la derecha, distribución acumulada del conjunto de muestras (ordenadas) en función de la concentrción de células de Nitzschia delicatissima en cada muestra, para la serie utilizada para trazar la distribución cartografiada en la figura 11, superior derecha. Abscisas en escala logarítmica, ordenadas según la escala de la distribución normal de probabilidades.
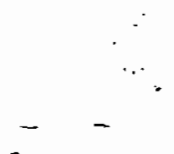
nos ciclónicos y con frentes marinos, en el mismo sentido que estamos comentando. Cooper (1960) supone que el paso de una depresión, en el verano, puede producir, por las mismas causas, una especie de faja o vía en que la superficie del agua se enriquece y conduce a una proliferación estival de plancton. SAINT-GuILY (1962) ofrece descripciones de estructuras ciclónicas, propicias al desarrollo de manchas de fitoplancton de poca diversidad, observadas en 1954 y 1955 en el Miediterráneo.

Estructuras aún menores, del orden de 2 a $10 \mathrm{~km}$ de diámetro, se manifiestan en aguas costeras, siendo generalmente empresa fácil descubrirlas midiendo la temperatura del agua con termistores aislados o en cadena. Su forma es redondeada o alargada. Datos más precisos sobre contenido en elementos nutritivos (fundamentalmente fosfatos) y las características de su plancton permiten caracterizarlos ulteriormente como centros de mínima madurez. En la Ría de Vigo se originan probablemente como resultado de la interacción entre las corrientes de marea e irregularidades del fondo, en forma de remolinos que duran quizá varios dias. Las figuras 9, 10 y 11 ilustran un ejemplo típico de las costas levantinas. Los datos publicados o inéditos que se poseen sobre dicha zona: permiten reconocer otros ejemplos semejantes. En el caso ilustrado, la estructura está mucho mejor definida biológica que hidrográficamente. La figura 14 ofrece otro ejemplo de la misma área, en una escala de dimensiones mucho menor : en un pequeño bloque de una milla cuadrada se manifiesta claramente un centro de mínima madurez. Todos los bloques parecidos que han sido estudiados (MARGaleF, 1961 a) permiten reconocer diferencias locales que se pueden expresar en términos de madurez. Existe, pues, una escala o espectro amplísimo en las estructuras caracterizables por diferencias de madurez. Algunas de las más pequeñas se pueden deber a un simple golpe de viento, que determina una mezcla vertical limitada o muy local. Dotr recuerda que en tales condiciones se manifiestan incrementos en la producción: puesto que destruyen una estructura estratificada preexistente, puede compararse hasta cierto punto con un fuego o incendio en la vegetación terrestre.

El mar posee una estructura hidrográfica probablemente más compleja de lo que se supone. CoOPER (1961) señala la existencia de numerosas discontinuidades que determinan una suerte de estratificación, a base de abolos» de agua que se supone deslízanse a lo largo de las superficies isopícnicas. Ésta serfa una forma habitual de realizarse el proceso al que se ha dado el nombre de acascading», nombre muy poco adecuado si se tiene en cuenta la pequeñez de las pendientes. Las corrientes de turbidez representan fenómenos comparables, por lo menos por su discontinuidad. El mismo CoOPER imagina que esta estructura discontinua puede representar un elemento de heterogeneidad en la distribución del plancton, que se distribuiria de acuerdo con las condiciones reinantes en las 


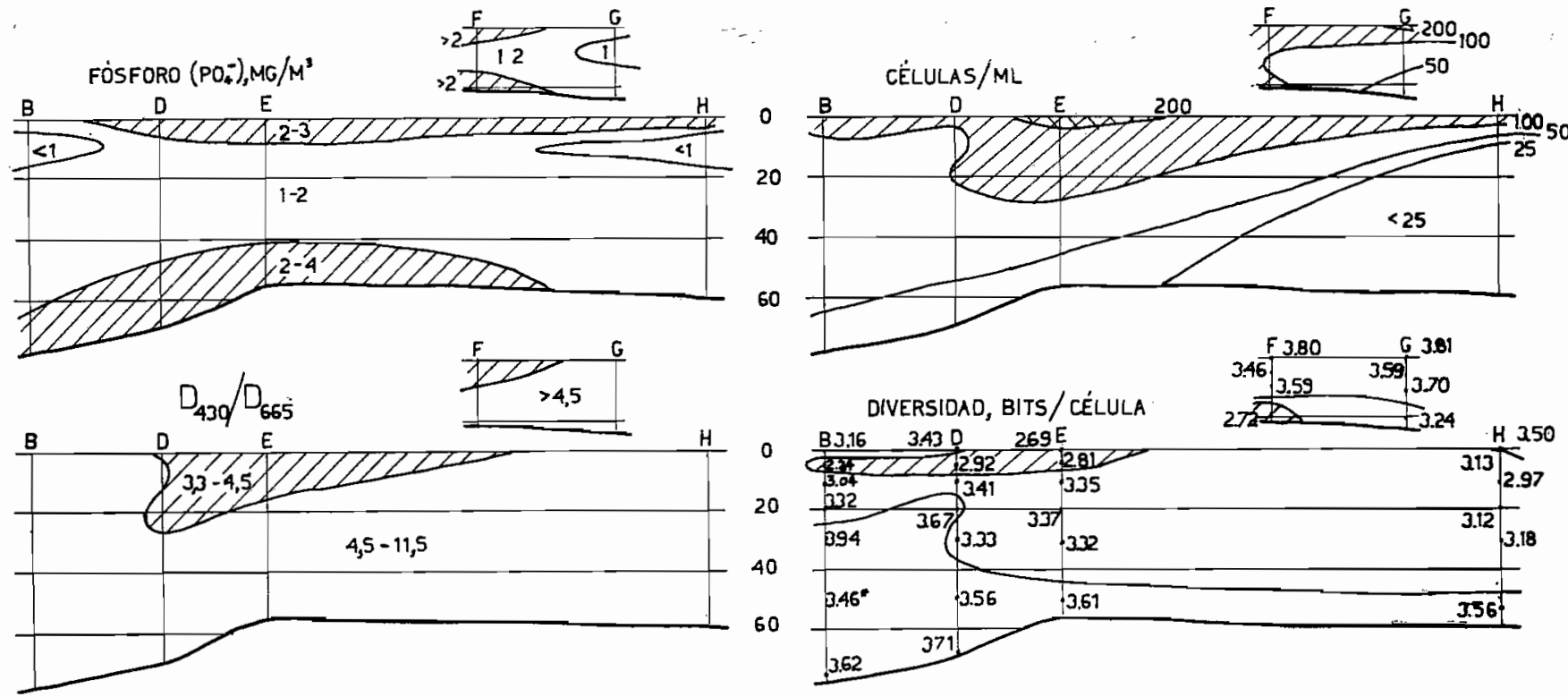

Fig. 10. - Concentración de fosfato inorgánico y algunas características del fitoplancton en una sección aproximadamente paralela a la costa, al sur del Ebro (fig. 9 ; se dibujan las dos secciones, más o menos paralelas, $F-G$ ₹ $B-H$ ), los días 9 y 10 de mayo de 1962. La concentración, en células por $\mathrm{ml}$, y la diversidad, en bits por célula, han sido basadas en recuentos hechos con el microscopio de Utermöhl. 

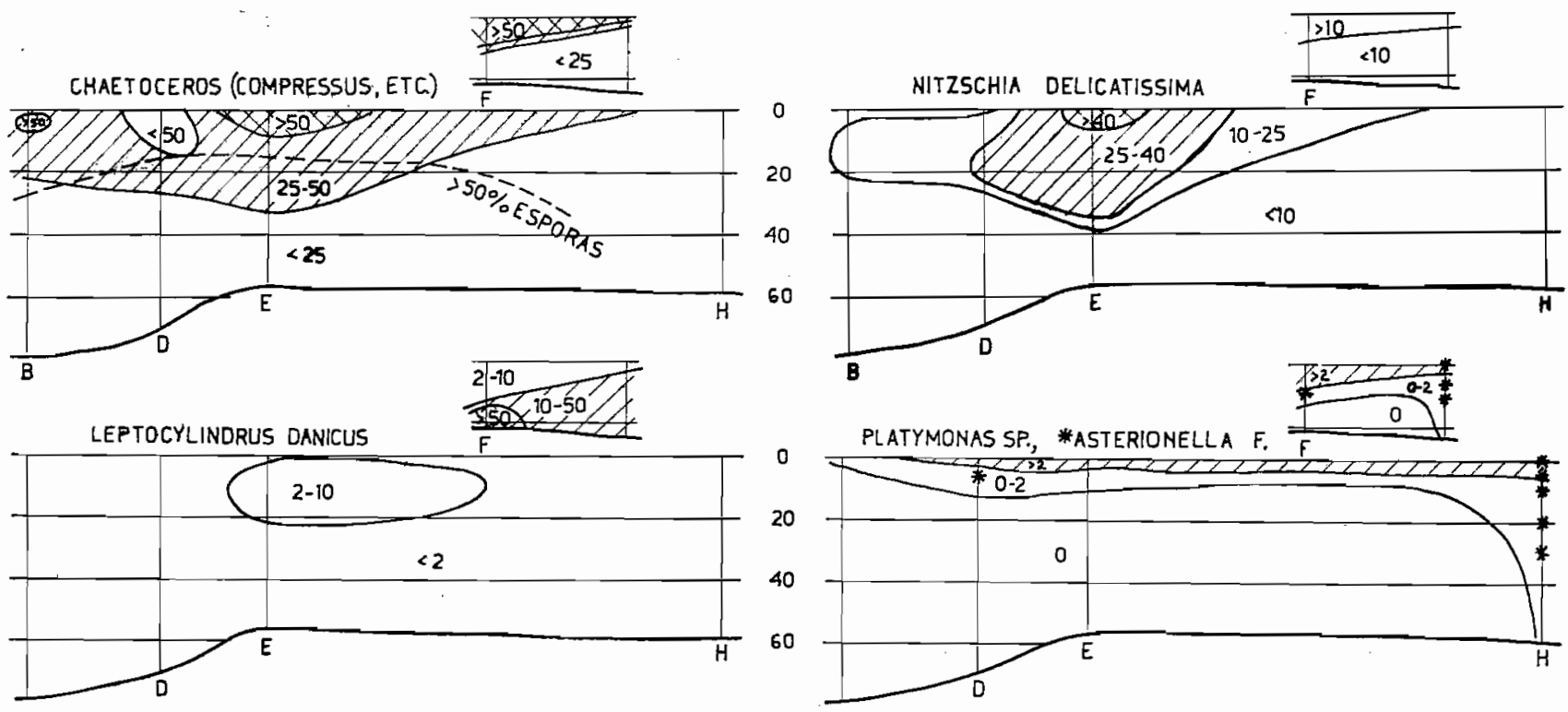

Fia. 11. - Distribución de varias especies en una sección aproximadamente paralela a la costa, al sur del Ébro, los días 9 y 10 de mayo de 1962 (véase fig. 9). Datos obtenidos con el microscopio de Utermöhl. En la figura superior izquierda hay una línea de trazos por debajo de la cual más del $50 \%$ de las células de Chaetoceros compressus y de algunas otras especies del mismo género y de pequeño tamaño habían formado hipnósporas. En la figura inferior derecha, el asterisco señala los puntos donde se recogieron células de Asterionella formosa, una diatomea de agua dulce que es acarreada en número considerable por las aguas del Ebro, y es indicadora de influencia de dichas aguas. Platymonas sólo prospera en estas con diciones. Chaetoceros compressus y Nitzschia delicatissima eran dominantes en una mancha de plancton que ocupaba la superficie en la estación E y cerca de ella. 
distintas masas de agua o escamas superpuestas, o según las particulares existentes en sus límites, donde pueden darse condiciones adecuadas a un mayor flujo de energía o menor madurez. Aunque más fugaces, estructuras de este tipo se presentarán sin duda en superficie. Entre otras causas, un río que desemboca en un mar sometido a corrientes que cambian de dirección y sentido es fuente de numerosas células de agua de densidad diversa que persisten más o menos tiempo y son asiento de heterogeneidad planctónica (aguas costeras de Castellón, bajo la influencia del Ebro).

Centros de máxima madureł y estructuras hidrográficas asociadas con ellos. - Mientras que un centro de mínima madurez aislado es de ocurrencia frecuente, es más difícil hablar de centros de máxima madurez. En general, las condiciones de gran madurez en las comunidades planctónicas suelen extenderse sobre áreas alargadas, en las costas, bahías, etc., interrumpidas o perforadas por los que pueden considerarse centros de mínima madurez.

Cualquier situación asociada a una acumulación de plancton y a una reducción de las posibilidades de producción (descenso de masas de agua, cuando el enriquecimiento en sustancias nutritivas no se produce con ld suficiente rapidez para compensar el decrecimiento de la iluminación) puede convertirse en un centro de máxima madurez. Lo son, pues, los torbellinos anticiclónicos o descendentes (LAEEvastu, 1962).

Un tipo equivalente de estructura, de dimensiones menores, aparece en las aguas de nuestro litoral, durante la primavera, como consecuencia de una intensa irradiación sobre un mar de superficie desigual. La transmisión de energía del aire al agua varía con las características de ésta. En las manchas naturales o artificiales de aceite o de otras sustancias tensoactivas, el agua está menos agitada, la pendiente media de la superficie del mar es menor, el calor absorbido por las capas superiores establece un fuerte gradiente, pues la transmisión turbulenta de calor hacia abajo es limitada y el mismo gradiente térmico obstaculiza la mezcla vertical ; la radiación reflejada o devuelta a la atmósfera es importante. En los lugares donde el agua está más agitada, existe un mayor transporte de calor de arriba abajo, se devuelve una proporción menor de radiación y es mayor la cantidad total de calor absorbida por una columna de agua equivalente. El equilibrio hidrostático pide que agua de estas porciones más agitadas ha de converger sobre las manchas de agua tranquila que tienen una temperatura muy alta en superficie. Ia termoclina profunda, si existe, se halla a mayor profundidad bajo las divergencias que bajo las convergencias. Fl proceso no es continuo, como no lo son la intensidad del viento ni la irradiación solar. Además, agua procedente de alta mar puede formar lentejas o escamas que se superponen a otras 
originadas en aguas más costeras, de manera irregular, con toda clase de deformaciones y corrimientos. Los perfiles térmicos pueden ilustrar sobre la edificación de una estructura que se vuelve paulatinamente más confusa. Las figuras 12 y 13 ilustran estructuras de este tipo en aguas de Castellón. Estos ejemplos corresponden a días en que no se manifestaron ondas internas notables o cambios rápidos en la hidrogiafía local. Otras veces las ondas internas complicaban el fenómeno. Estas ondas

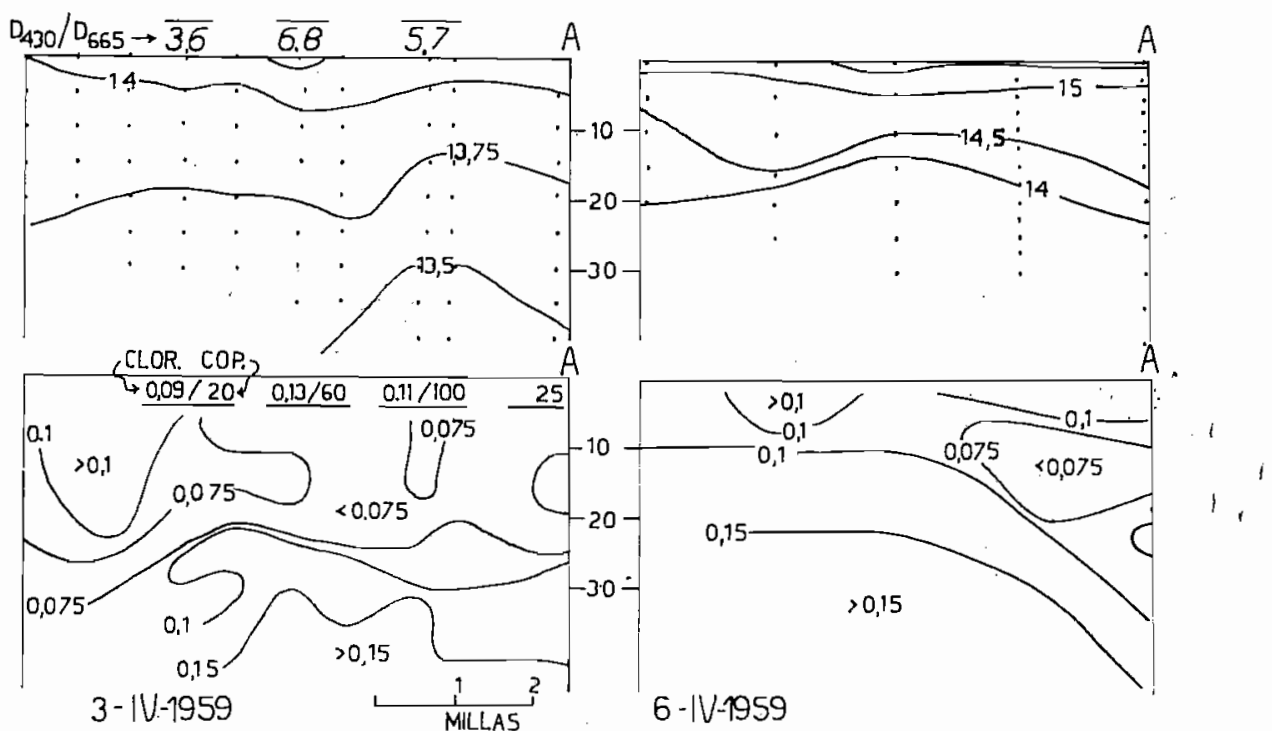

Frg. 12. - Secciones aproximadamente perpendiculares a la costa, a partir de unas dos millas de la misma (margen izquierdo de las figuras) y alcanzando hasta la estación A (que queda a media distancia entre la costa y la estación B de fig. 9), en aguas de Castellón, durante el mes de abril de $1959, y$ en dos fechas próximas. Arriba, temperaturas; abajo, extinciones calculadas sobre los valores de iluminación medidos a distintos niveles con una célula de sulfuro de cadmio, con gran sensibilidad para la longitud de onda de 520 milimicras (Margater y Herrera, 1963 a). Obsérvese que las extinciones son mayores a profundidad y cerca de la costa. En los gráficos de la izquierda se señalan algunos caracteres del plancton de superficie: en el de arriba, el cociente $D_{430} / D_{005}$, que es máximo hacia el centro del gráfico (agua que pasa de $\left.14,25^{\circ} \mathrm{C}\right)$; en el de abajo, concentraciones de clorofila $a$ en $\mathrm{mg} / \mathrm{m}^{3}(0,09,0,13,0,11)$ y cuncentraciones relativas de copépodos $(20,60,100,25)$. La mayor diversidad de pigmentos y mayor riqueza de zooplancton parece ir asociada a una estructura convergente de fuerte gradiente vertical.

internas se manifiestan más tarde, en pleno verano. El 23 de julio de 1959 , en estos mismo parajes, la isoterma de $26^{\circ}$ mostró fluctuaciones de 5 metros según la vertical, entre los 5 y los 15 metros, y FraseTTo (1960) y FrasetTo, Backus \& Hays (1962) han descrito importantes ondas internas en el Mediterráneo meridional que, sin duda, se propagan sobre amplias extensiones. 
El fenómeno anteriormente descrito es digno de cuidadosa consideración, porque nos ofrece un ejemplo de cómo una pequeña causa (quizás una simple mancha de aceite en la superficie) conduce a una estructura que espontáneamente aumenta de organización y de escala de dimensiones, lo mismo que un sistema orgánico. Como es de prever, los centros o convergencias de estas estructuras, cuya escala de dimensiones se puede

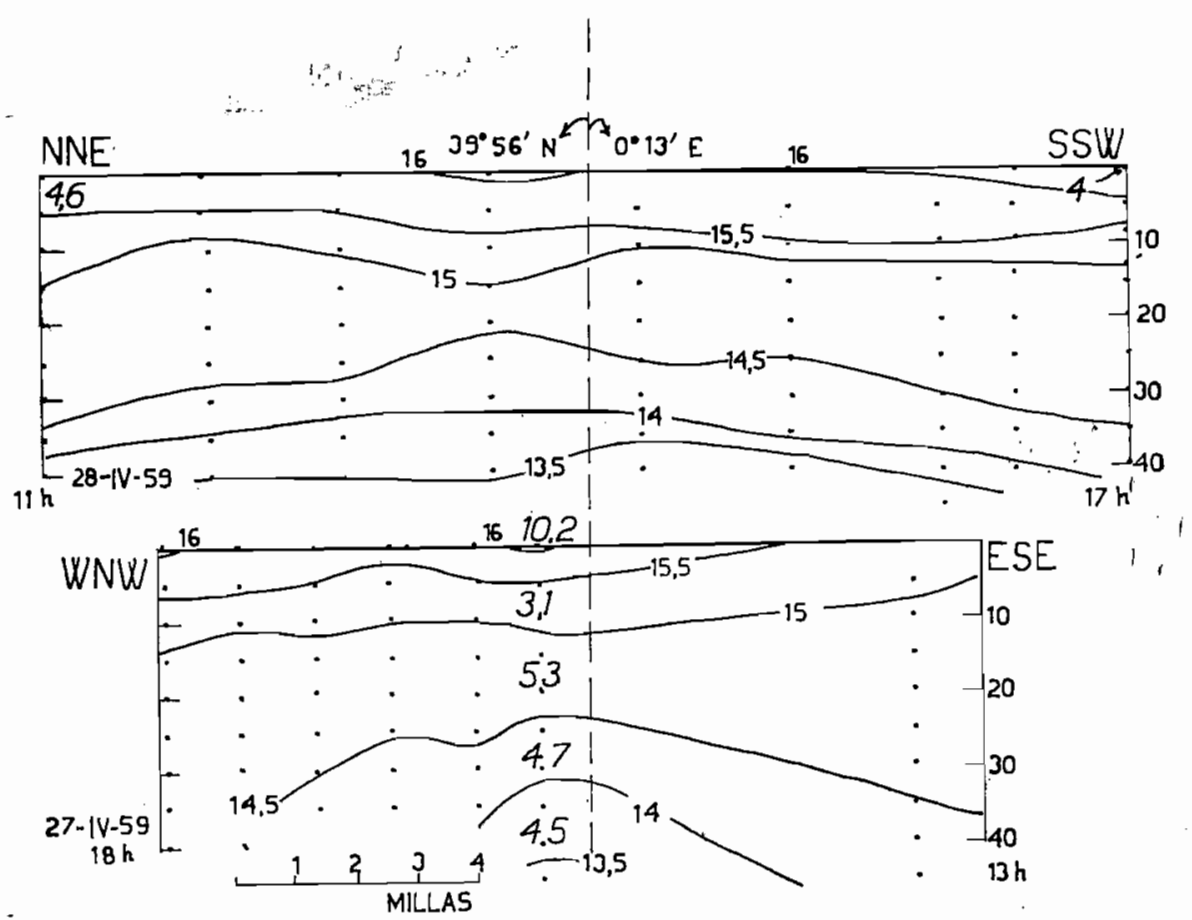

Fia. 13. - Isotermas observadas en dlas consecutivos (27 y 28 de abril de 1959) en dos secciones en aguas de Castellón. La sección del esquema superior es aproximadamente paralela a la costa, de NNE a SSW, a unas 8-9 millas de la costa, desde frente Burriana a frente a Oropesa. La sección inferior va de WNW a ESE, desde la costa, pasando por la estación $A$ hasta la $B$ (fig. 9). Las dos secciones se cruzan en el punto cuyas coordenadas geográficas se indican, situado cerca de la estación A y un poco al Eiste de la misma, y cuya posición se señala en los dos gráficos por la línea vertical de trazos. Los números en cursiva dan unos cuantos valores del cociente $D_{4 s a} / D_{\text {a }}$. El máximo se halla en la superficie de un lugar donde el gradiente vertical es muy fuerte $y$ donde existía probablemente una pequeña convergencia $o$ estructura descendente.

ver por las figuras citadas, albergan un plancton de características más maduras, mayor diversidad específica, mayor cociente $D_{430} / D_{005}$ y mayor proporción de zooplancton. Ciertamente, la existencia de gradientes fuertes sobre distancias muy limitadas ha de hacer que estas estructuras puedan servir de referencia para la agregación de variados animales ma- 
rinos, incluyendo los peces ; pero todavía no se poseen los datos necesarios para un análisis del problema, con sus posibles implicaciones prácticas.

El tipo inverso de estructura, que debería esperarse en otoño, cuando el agua superficial se enfría más intensamente en un lugar que en los vecinos, carece de importancia, porque el enfriamiento del agua aumenta su densidad y destruye la estabilidad de la estructura.

Masas de agua flotantes poco densas, a veces muy pequeñas (20-100 metros) se expulsan intermitentemente en estuarios o bahías, siendo las mareas agentes muy efectivos, pero no exclusivos, de su discontinuidad
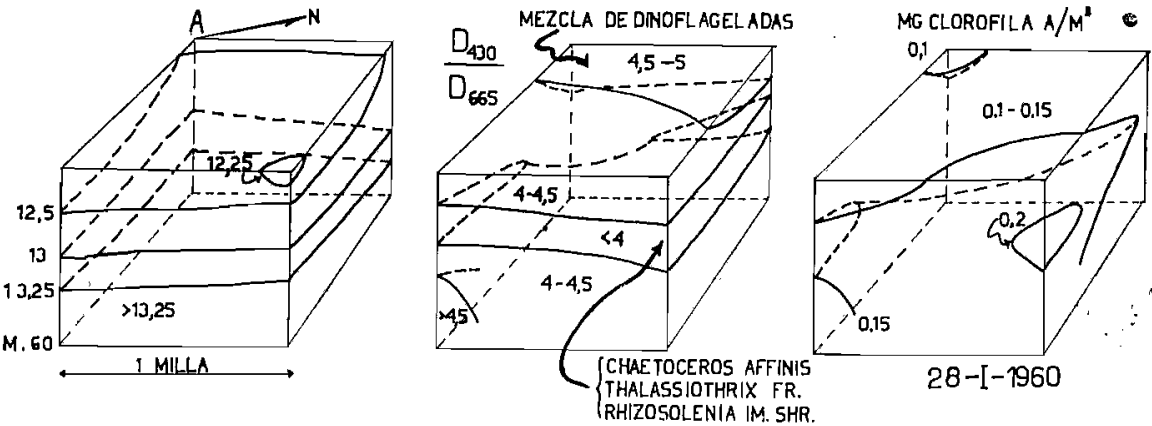

FIG. 14. - Gradientes bastante fuertes en un pequeño bloque de 1 milla por 1 milla por 60 metros, junto a la estación A, en aguas de Castellón (fig. 9), a fines de enero de 1960. A la izquierda, temperaturas, con inversión. En el centro, distribución del cociente $D_{480} / D_{045}$; los valores bajos corresponden a aguas con proliferación de Chaetocoros affinis, Thalassiothrix frauenfeldii, Rhizosolenia imbricata shrubsolei, ete.; los valores altos se hallan cerca de la estación A, donde existe importante mezcla de dinoflageladas (Ceratium furca, Ceratium tripos, Ceratium candelabrum, Diplopsalis asymetrica, Peridinium brochi, Ceratium pentagonum, Ceratium massiliense, Prorocentrum micans, Peridinium depressum, Goniaulax polygramma, Protoceratium areolatum, Phalacroma parvulum, Ceratium strictum, Ceratium asoricum, Ceratocorys armata, Blepharocysta paulseni, Ceratium fusus, Ceratium concilians, Peridinium arassipss, Ceratium aristinum, Ceratium trichoceros, Ptychodiscus inflatus, Ceratium symmetricum, Ceratium limulus, Oxytoxum sp., Ornithocercus magnificus, Gonianlax digitale, Ceratium extensum, Peridinium steinii, Ceratium buceros, Dinophysis caudata). No se hicieron recuentos, pero la diversidad biótica era ciertamente más elevada en el borde superficial y occidental del bloque estudiado. A la derecha, concentración de clorofila $a$ en $\mathrm{mg} / \mathrm{m}^{3}$.

(Slobodrin, 1953; Chew, 1956 ; Hela, 1955; Margalef, 1961 ; Ragotzkie \& Pomeroy, 1957; Lafond \& Borreswara, 1954; Lafond, 1954 ; MUNK, 1955 ; RosENGoURTH, 1962). Estas «burbujass flotantes son frecuente asiento de poblaciones muy maduras, como las que producen las aguas rojas, purga de mar o hematotalasia.

La relativa discontinuidad hidrográfica de estas manchas afsla bastante efectivamente las poblaciones, aún más si se tiene en cuenta que éstas suelen estar formadas por organismos que nadan activamente. Mientras que SLOBodrin estudia la persistencia de estas poblaciones en térmi- 
nos de la tasa de multiplicación y de la difusión de los organismos, CHew (1956) cree que el problema ha de circunscribirse a estudiar la persistencia de la masa lenticular de agua que contiene el plancton. Este autor calcula el valor que ha de tener el ángulo formado con la superficie por la tangente que separa la mancha de agua desalada y el agua circundante en función de las densidades, velocidades, aceleración de la gravedad y fuerza de Coriolis. Pero se puede estudiar igualmente la difusión de los organismos planctónicos sin más que tener en cuenta que las condiciones de movilidad y difusión varían en la superficie de discontinuidad que define el borde de la mancha y que se altera constantemente.

Otras estructuras asociadas con poblaciones de máxima madurez se presentan siempre en multitud $\mathrm{y}$ por esto se mencionan en la sección siguiente.

\section{SISTEMAS CON MULLTIPLES CENTROS O FOCOS DE DESIGUAL MADUREZ}

Centros de máxima madurez y estructuras hidrográficas correspondientes. - Los centros de máxima madurez en un nivel dado, raramentẹ aparecen aislados ; suelen presentarse (en familias», asociados frecuentẹmente con manchas visibles y alargadas ( «slicks») que se disponen paralelamente, con mayor o menor regularidad y que se manifiestan de manera aparatosa en los casos de "purga de mar» (BARY, 1953 ; BAINBRIDGE, 1957 ; Tsujita, 1955 ; Margalef, 1956). Son convergencias en las que se acumulan los organismos nadadores. Se producen por la acción de un viento que sopla según el sentido de alargamiento de las manchas (LANGMUIR, 1938 ; WINGE, 1923 ; WoODCOCK, 1944, 1950 ; WoODCOCI \& WYMAN, 1947 ; LANGMOIR \& WOODCOCK, 1941), pero también pueden ocurrir sin viento, como consecuencia de ondas internas (EwING, 1950; LAFOND, 1962). Aparte de los casos mejor conocidos de la purga de mar, Rodbault (1946) hace notar diferencias en la composición del plancton, dentro y fuera de estas fajas, en el Mediterráneo. Los "slicks» se reconocen fácilmente, porque sobre las convergencias se acumulan sustancias tensoactivas, espumas y suciedades flotantes, que les dan un aspecto mate. Su anchura es de decenas a centenas de metros.

Células convectivas de dimensiones minimas. - En las células convectivas alargadas que hasta ahora considerábamos, los flagelados se concentran en las convergencias, bajo las fajas de superficie mate, y mantienen su nivel nadando hacia arriba, buscando una intensidad luminosa adecuada. Estos organismos realizan migraciones diurnas verticales de pocos metros (Pomeroy \& al,, 1956 ; Margalef, $1961 \mathrm{c}$; Hasle, 1954 ; HiLA, 1955). 
Pasando a un nivel de dimensiones inferior, como se da en el laboratorio $y$, posiblemente, en la naturaleza, bajo circunstancias especiales, aparecen nuevos efectos de elevado interés. Espontáneamente se pueden formar sistemas de convergencias y divergencias por actividad de los propios organismos. Según Crisp (1962), la natación de los Gymnodinium y de nauplios de Eliminius determina la aparición de pequeñas convergencias. El movimiento ascensional de los organismos y el aumento de densidad que representa su acumulación - como en una corriente de turbidez - hace que la columna de agua en la que se concentran descienda lentamente. Ocurre lo mismo que con un grupo de helicópteros, que ai aproximarse o superponerse pierden la fuerza ascensional por inestabilidad dinámica. Euglena, Tetrahymena, Paramecium y espermatozoides dan lugar a situaciones semejantes (PLATT, 1961).

La actividad de estos organismos produce una serie de células de circulación adosadas, con ascensión y divergencia en el centro de cada célula y convergencias que trazan una especie de panal. La densidad de los organismos en las convergencias es hasta cien veces superior a la que se observa en el centro de las divergencias. Las divergencias son lugares de expansión de la población ; las convergencias, lugares de concentración ; si hay flujo de energía, va de las divergencias a las convergencias; los movimientos son más ordenados en las convergencias que en las divergencias. También aquí, pues, y sin abandonar o modificar los criterios hasta ahora seguidos, las convergencias se pueden considerar como lugar de poblaciones más maduras que las que se encuentran en las divergencias.

Estructuras en forma de panal. - La estructura a pequeña escala que se acaba de describir tiene forma de panal ; los centros de menor madurez, en las divergencias, son puntiformes, mientras que los centros de mayor madurez, en las convergencias, forman un retículo.

Cuando se tiene un gran número de especies desigualmente distribuidas, con los respectivos centros de máxima abundancia repartidos más o menos uniformemente en el espacio, la distribución de la diversidad muestra mínimos puntiformes y méximos situados también a lo largo de un retículo que rodea o encierra a aquellos puntos.

El mismo tipo o motivo de estructura se manifiesta en muchos fenómenos físicos. Las células de convección, tanto en las nubes como en los gránulos de la fotosfera solar, son núcleos de intenso intercambio de energía en el seno de una masa envolvente más uniforme y estable. En el agua de mar, la formación del hielo se inicia en puntos separados; al ir cristalizando el agua se produce una migración de sales hacia el espacio periférico limitante entre las celdillas y que podría decirse tiene mayor diversidad. Se trata de simples analogías, desde luego, pero que recuerdan 
lo frecuente que es en cualquier sistema físico, formado por fases diferentes, el que estas fases no ocupen irregularmente espacios comparables al modo de las piezas de un mosaico, sino que exista cierta estructura y ésta sea precisamente en panal y de tal tipo que las porciones divergentes, menos estructuradas o con mayor cambio de energía, ocupan los centros de las celdillas.

En cualquier área marina extensa se manifiestan complicadas variaciones en la madurez; existen, por lo general, gradientes suaves de gran escala, a los que se superponen estructuras menores. Pues bien, estas estructuras menores son más frecuentemente rodales ide escasa madurez incluidos en un fondo más maduro que no el motivo o dibujo inverso. En todo caso, este motivo inverso, constituido por pequeñas convergencias con Goniaulax, clodóceros y Noctiluca sembradas en un volumen de características menos maduras, ocurre de manera excepcional y es más transitorio. En todo sistema de convergencias y divergencias alternadas, la expansión del agua en las divergencias tiende a fusionar unas con otras a las zonas de convergencia, que quedan rodeando a las divergencias más o menos puntiformes.

No se poseen estudios sistemáticos hechos con el suficiente detalle; pero los indicios indirectos y las observaciones parciales son numerosos. Las manchas de fitoplancton, especialmente de las especies características de las comunidades menos maduras, son redondeadas; mientras que las manchas de zooplancton muestran frecuentemente contornos irregulares o recortados. Esta estructura cobra relieve vista en la perspectiva de la sucesión. El ciclo anual, en latitudes altas, se inicia frecuentemente con centros distintos de proliferación del fitoplancton, alrededor de los cuales se reúnen y multiplican luego los organismos del zooplancton que se sustentan de las algas (ManteufeL, 1941).

Es casi obligado expresar la esperanza de que pronto sea posible referir esta estructura en panal a propiedades básicas de los ecosistemas, de cualquier arsociación de sistemas de distinto grado de organización. Se puede especular que la adopción de una forma reticular por el subsistema más organizado es una situación a la que se tiende en cualquier sistema compuesto por subsistemas de distinto grado de organización.

\section{DISTRIBUCION DE POBLACIONES UNIESPECIFICAS EN UN SISTEMA ANISOTROPO}

Se ha llegado al concepto de isotropía o anisotropła en un ecosistema, estudiando la distribución en el espacio de la estructura que resulta de la superposición de un número teóricamente ilimitado de distribuciones uniespecíficas. Luego el concepto se amplía con la inclusión de puntos de 
vista de la termodinámica y de los llamados sistemas generales. Puede ser útil volver a descender al nivel de las distribuciones uniespecificas; pero sin abandonar las nuevas perspectivas adquiridas en la ruta de la inducción. Así es posible afirmar que en los lugares de menor madurez se encontrarán especies con un mayor flujo de energía por unidad de biomasa, es decir, de vida media corta, de elevada tasa de multiplicación, de altio metabolismo - entre otras caracteristicas, de pequeño tamañoy carentes de los dispositivos anatómicos, fisiológicos y etológicos que se consideran como adaptaciones a condiciones de vida muy estables. Por el contrario, serán propias de áreas de mayor madurez las especies die vida más larga, si son algas, con una variedad mayor de pigmentos y concentración total de los pigmentos menor, y en las que la movilidad propia sustituye a la turbulencia del medio para facilitar la absorción de elementos nutritivos, si son animales dejarán un número de descendientes más limitado y protegerán mejor a su prole. Toda clase de defensas -mimetismo, homocromía, tóxicos-, ritmos internos e instintos ajustados testimonian su adaptación a un sistema mucho más organizado.

Fxisten especies cuyos individuos se extienden sobre áreas amplias en las que pueden manifestarse diferencias de madurez. En tales casos la estructura demográfica varía de unos a otros lugares. Da lo mismo decir que el tipo de distribución estadística varía con la edad (СомітA y ComI$\mathrm{TA}, 1957)$. Es general que en las áreas de menor madurez se encuentre una población más juvenil, con un mayor flujo de energía por unidad de biomasa, mientras que las clases de edad más avanzada sean progresivamente más frecuentes en las áreas que corresponden a la naturaleza más madura de los ecosistemas. Ello se debe, en el caso de animales pelágicos, a que las zonas de cría coinciden con los centros o focos de poca madurez, donde existe un gran flujo de energía que la especie utiliza en su provecho, sin tropezar con fuerte competencia. Por la simple dispersión y crecimiento de los individuos, la estructura demográfica de la población se va haciendo más vieja a medida que aumenta la distancia al centro de crla (MARgALEF, 1957 a). La zona más importante de cria de la sardina en el área.de Castellón coịncide con las proximidades del río Ebro, donde se tiene, en general, la menor madurez, y a medida que se avanza hacia el Sur o aguas afuera, aumenta también la proporción de individuos de más edad en las poblaciones. En poblaciones de Chaetoceros la aparición de esporas es más frecuente en las partes más maduras del ecosistema (fig. 11). Este principio general se manifiesta de modo especialmente claro en los animales bentónicos cuyas larvas viven y se sustentan en un sistema menos maduro, el que corresponde a las aguas libres. La existencia de larvas planctónicas representa una de las varias formas en que el bentos — subsistema más maduro- explota al plancton — subsistema menos maduro-. 
Los peces migratorios suministran otros ejemplos instructivos. Las anguilas cumplen su desarrollo larvario en un sistema menos organizado - las aguas oceánicas libres- que aquel en el que se desenvolverá la vida de los adultos — tramo bajo de los ríos, estanques-. Los salmones, a su vez, explotan en su fase juvenil uno de los sistemas menos organizados de las aguas dulces - los tramos altos de los cursos de agua-, mientras que los adultos se integran en un sistema litoral con caracteristicas de mayor niadurez.

Casi no hace falta recordar cuán frecuentes son, en las proliferaciones de fitoplancton - manchas de poca madurez-, los estados larvarios de numerosos organismos del zooplancton cuyas poblaciones tienen una estructura demográfica más vieja en las agnas circundantes. Esta diferencia se manifiesta de modo particularmente claro en el sentido vertical: es una regla general que las poblaciones de animales pelágicos contengan una mayor proporción de jóvenes en las capas más superficiales, en las porciones menos maduras del ecosistema pelágico en general.

\section{EL QUEMOSTATO COMPUESTO COMO MODELO ' DE ESTUDIO DE ECOSISTEMAS PELAGGICOS}

Cultivos sin flujo del medio. - El balón de plástico, lleno de agua profunda y del que se han excluido los animales del microplancton, empleado por MCALLISTER y colaboradores (1961), representa una uburbuja» menos madura sumergida en el seno de un ecosistema de características algo más maduras y que evoluciona con el tiempo hacia caracteristicas de una madurez creciente. Se podria especular sobre la naturaleza del intercambio que se establecería a través de algunos agujeros que hiciéramos al balón. Ciertamente existirfa un flujo neto de fitoplancton hacia el exterior y entrarían animales que podrían luego multiplicarse en el interior del balón y complicar la estructura de su población mixta. En otras palabras, el subsistema menos maduro exportaría energía potencial al más maduro y éste ejercerf́a una influencia organizadora sobre el primero. Al modelo de laboratorio se le pide la comprobación y expresión cirantitativa de semejantes regularidades.

Los cultivos en columna, como el descrito en una comunicación anterior (Margalet, 1963 a), se prestan a estudios de esta clase. En un cultivo de gran extensión vertical se consigue deslindar dos subsistemas, uno menos maduro en la parte superior y otro más maduro en la parte inferior. Pero el sistema carece de la flexibilidad suficiente para servir de base a un estudio experimental completo de los problemas planteados.

El quemostatio. - La forma más sencilla de quemostato consiste en. un recipiente de cultivo, cuyo contenido se mantiene agitado y está so- 
metido a un flujo constante. Recibe medio de cultivo nuevo y, simultáneamente, abandona el recipiente un volumen igual del medio que lleva en suspensión la población allí desarrollada, en su densidad media. Los principios del quemostato han sido discutidos por diversos autores (N.oVIOK, 1959 ; Moser, 1958 ; Coutols, 1959 ; Powell, 1958 ; JanNasoH, en prensa). La densidad de población en un quemostato se ajusta automáticamente a la tasa de multiplicación de la especie presente y al flujo en el medio de cultivo. Si la multiplicación aumenta, es también mayor el número de células que abandona el cultivo y el equilibrio se restablece en un nivel distinto. La única condición es que el flujo, expresado en la fracción del volumen total del cultivo que es trasegada en una unidad de tiempo $(F)$, no puede exceder del que corresponde a la tasa de multiplicación potencial de la especie $(r)$ en aquellas condiciones :

$$
r \geqq \log _{e}(1+F)
$$

Si el flujo es excesivo para la tasa de multiplicación, la población es arrastrada. Puesto que no es probable encontrar dos especies que tengan exactamente la misma tasa de incremento bajo condiciones definidas, el quemostato simple (o el primer recipiente de un quemostato compuesto) permite conseguir una población uniespecífica. Con el quemostato es posible estudiar los efectos sobre la población de un constituyente adecuadamente dosificado en el medio de cultivo.

El quemostato simple es un análogo de ciertas situaciones que se presentan en planctología. El problema de averiguar el espesor máximo de la profundidad de mezcla para el que el fitoplancton empiece realmente a proliferar, se deja plantear cómodamente en un quemostato, determinando el flujo máximo compatible con el desarrollo de una población mixta de fitoplancton cuyos gérmenes se van introduciendo a la vez que el nuevo medio de cultivo. Supongamos que hemos empezado con un flujo muy intenso y que lo vamos reduciendo: llega un momento en que las células inoculadas se multiplican y persisten en el recipiente. Entonces es posible interrumpir la inoculación y se puede observar como la primera población que se desarrolla es extraordinariamente sencilla: ejemplo de la dominancia de, generalmente, una sola especie y modelo de las proliferaciones vernales de fitoplancton.

El quemostato se presta también a reproducir situaciones que existen en un estuario, en un río, en un afloramiento de aguas profundas.

Quemostatos compuestos. - Las ventajas que ofrece este tipo de experimentación se multiplican cuando conectamos en serie varios recipientes de cultivo continuo (Margales \& Ryther, 1960), de manera que la suspensión de organismos que abandona el primer vaso constituye el aflujo al segundo recipiente, el cual puede recibir además un aflujo es- 
pecial de determinados elementos nutritivos. No hay inconveniente en conectar linealmente un número grande de recipientes. En un mismo recipiente se tiene una población que continuamente persiste en el mismo estado dinámico, mientras que los estados por los que pasa sucesivamente una población real, se hallan en recipientes sucesivos. E1 quemostato compuesto ofrece una proyección en el espacio de un fenómeno temporal, de la historia de una población. Puesto que muchas, por no decir todas, las heterogeneidades que se observan en el plancton son, asimismo, una proyección en el espacio de fenómenos históricos, el quemostato compuesto es un instrumento muy adecuado para estudiar las regularidades en las estructuras espaciales del plancton y explicarlas y expresarlas cuantitativamente.

Sea $N_{i}$ la concentración de células de una especie en el recipiente $i$ de la serie, $r_{i}$ su tasa instantánea de multiplicación en dicho recipiente, $F$ el flujo, tal como se ha descrito anteriormente, $y$ la tasa instantánea de flujo $\left[f=\log _{e}(1+F)\right]$. Tendremos las expresiones siguientes :

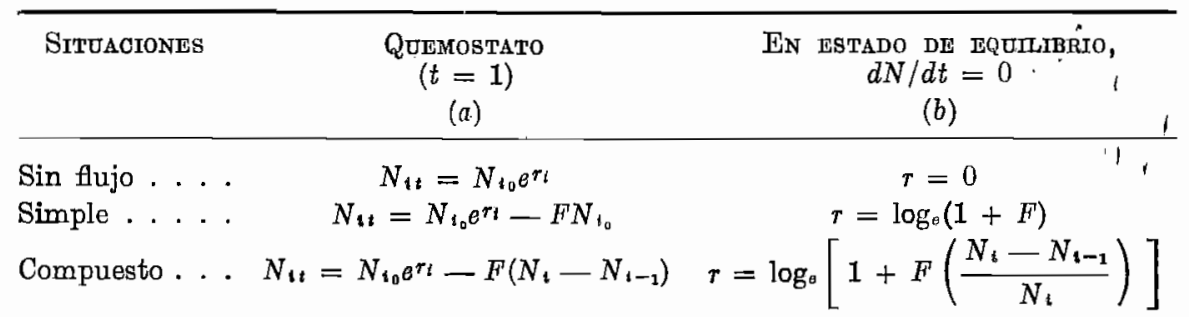

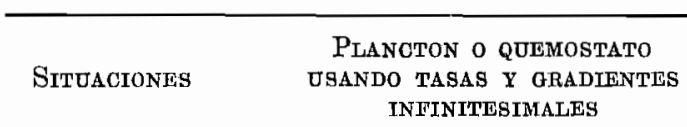

(c)

\begin{tabular}{cc}
\hline Sin flujo ... & $d N / d t=r N$ \\
Simple . . & $d N / d t=r N-f N$ \\
Compuesto . . & $d N / d t=r N-V \frac{d N}{d x}\left(^{*}\right)$
\end{tabular}

EN IESTADO DE EQUHIBRIO, $d N / d t=0$

(d)

(*) Esta expresión se aplioa propiamente a un tubo de cultipo más que a un quemostato subdividido en cómaras. $V$ es la velocidad del medio en el tubo. $k_{n}$ es el gradiente de densidad de las células $\left(N_{\sigma}=N_{0} e^{k_{n} a}\right)$, siendo $x$ la distancia en el sentido de avance del liquido.

Pudiera parecer que el cultivo en un tubo de diáme sro uniforme, cuyo contenido está sometido a un flujo determinado, ofrece ventajas sobre el modelo constituido por una serie de recipientes agitados y unidos unos con otros por medio die tubos de poco diámetro en los que el flujo puede considerarse laminar. Pero el tubo, a pesar de la aparente elegancia de 
su continuidad, presenta dos grandes inconvenientes : 1 , no puede proporcionar una muestra homogénea de volumen suficiente para los análisis con la misma facilidad que un quemostato formado por recipientes de 300-500 $\mathrm{ml}$ de capacidad, y 2, es incapaz de mantener el cultivo en condiciones de flujo laminar, porque la población debe empezar en algún lugar dentro del tubo, donde el gradiente $k_{n}$ se hace infinito y la población es fatalmente arrastrada por pequeña que sea la velocidad. Obligados a aceptar la turbulencia, ésta resulta mucho más controlable en un sistema formado por recipientes relativamente grandes y constante o intermitentemente agitados.

En un quemostato compuesto se pueden representar de manera suplementaria los efectos de la turbulencia, enlazando dos elementos próximos de manera que su contenido se mezcle, cambie y uniformice con una reiteración o frecuencia determinadas. El flujo ya no es exclusivamente en un solo sentido, sino que se pueden fijar segmentos o cámaras de mezcla, tal como se hace teóricamente con ríos y estuarios sujetos a corrientes y a mareas (Pritchard \& KeNT, 1956; Ketchom, 1954). Si existen $X$ ciclos completos de mezcla entre dos vasos contiguos por unidad de tiempo tendriamos las siguientes expresiones, que se escriben de manera que se correspondan con las cuatro columnas de la página anterior, incluyendo también las correspondientes al modelo infinitesimal :

(a) $\quad N_{t t}=N_{t 0} e^{r_{t}}-F\left(N_{t}-N_{t-1}\right)+X\left(N_{t-1}+N_{t+1}-2 N_{t}\right)$

(b) $\quad r_{1}=\log _{e}\left[1+F\left(\frac{N_{i}-N_{i-1}}{N_{i}}\right)+X\left(\frac{N_{i-1}+N_{i+1}}{N_{i}}-2\right)\right]$

$$
\begin{aligned}
d N / d t & =r N-V \frac{d N}{d x}+A \frac{d^{2} N}{d x^{2}} \\
r & =A \frac{1}{N} \frac{d^{2} N}{d x^{2}}-V k_{n}
\end{aligned}
$$

Es posible simular otro efecto en los quemostatos compuestos: las aceleraciones y retardos en el flujo, permitiendo que el volumen de algunos de los recipientes de cultivo aumente (se incrementa la velocidad del afluente a dicho recipiente, en relación con su emisario, o se retarda éste) o disminuya (se incrementa la velocidad del emisario sobre la del afluente).

Realización práctica de modelos constituidos por quemostatos compuestos. - Hasta ahora sólo se ha trabajado con quemostatos en serie simple y convergente, es decir, dos series lineales que confluyen en otra. Se creía que este dispositivo serfa muy útil para estudiar el resultado de la interacción entre dos poblaciones que se mezclan; pero en el recipiente donde se realiza la mezcla y en todos los sucesivos, se duplica el flujo, 
con efectos definidos sobre el resultado de la competencia, que no siempre corresponden a los modelos naturales o a los efectos deseados. Es conveniente construir un sistema tal en que los flujos sean constantes en todos los recipientes, o bien que disminuyan en los más alejados del punto de origen. Esta condición sería más realista, pues corresponde a una masa de agua en cuyo centr'o se introduce el medio nuevo, o ciertos elementos nutritivos — sería el primer recipiente de la serie- y que está rodeado de volúmenes concéntricos en los que el flujo disminuye según el cuadrado de la distancia al centro.

Fundamentalmente, un quemostato compuesto de uso general estará formado por un gran número de recipientes de cultivo que pueden conectarse unos con otros según un retículo de tres dimensiones. Como es natural los recipientes de cultivo no necesitan estar ordenados precisamente de acuerdo con dicho retículo : basta que los tubos de comunicación se ajusten a las relaciones topológicas correctas. Estos tubos conviene que sean flexibles y el flujo o intercambio entre unos y otros recipientes puede ser forzado por bombas peristálticas, programadas de acuerdo con el plan de circulación. Como es natural, pueden regularse adecuadametite las condiciones de temperatura y luz de las distintas vasijas de cultivo olvidar una agitación adecuada común a todas.

Actualmente está en plan de desarrollo este proyecto, habiéndose salvado ya algunas de las dificultades que se han ido presentando. Como objetivo se prevé la posibilidad de disponer el modelo de forma que los distintos recipientes del sistema correspondan a propiedades observadas en otros tantos puntos de un retículo de tres dimensiones en una masa de agua. Luego se experimentan las alteraciones posibles, introduciendo, por* ejemplo, elementos nutritivos en cierto punto, regulando los flujos, para imitar diferentes valores de difusión según las dimensiones, y buscando nuevos estados, transitorios o estacionarios del sistema. Cada depósito del quemostato equivale a un punto en un gradiente natural ; pero proporciona una cantidad de material suficiente para estudios de biomasa, composición biótica, pigmentos y productividad. Finalmente, es posible confinar a animales en algunos de los recipientes, impidiendo su expansión por todo el sistema por medio de redes o tamices adecuados en los tubos de conexión.

\section{S. U M A R Y}

Some regularities in the distribution of population of phytoplankton in a small and medium scale, and in their functional properties. - The most usual topics on heterogeneous distribution of phytoplankton and patchiness are discussed again. In unispecific populations, multiplication and diffusion in a non uniform environment leads commonly to a type of distribution in which density of population decreases exponentially with increasing separation from a center of maximum density. If 
samples are taken with a regular specing - distances between stations approximatively equal- or with a regular periodicity, it is only natural to find a lognormal distribution of densities in a series of samples. For some purposes, the ecologist may consider irrelevant if some niche is occupied by this or that species, and in fact, the sum of heterogeneous distributions at specific level can give a rather uniform distribution at the community level. We can have very similar values in productivity, in biomass, in pigment composition, in diversity, over a large area, even with a specific composition that changes more or less from place to place. Such a mixed population can not be named uniform and perhaps it would be convenient to name it isotropic. It follows that an anisotropic community will be integrated, also, of course, by a number of heterogeneous specific distributions, buts the pattern of their superposition results in a system that shows local differences in the synthetic properties to which reference has been made. Such synthetic properties are interrelated: primary production per total biomass is negatively correlated with complexity of the community, as expressed in the index of diversity (expression of the pattern of distribution of individuals into species) or in the pigment index $D_{150} / D_{005}$.

Most of mixed populations extending over a considerable area show a certain amount of anisotropy. Cyclonic eddies, small divergences, have the core occupied by a population with a high energy flow and rather small complexity. This may coincide or not with patches of a definite species. In convergence cells, such as occur in red tide outbrealss, slicks and, in spring, in the coastal mediterranean waters, more «mature» populations, with a lower primary production per total biomass and with a higher diversity, and higher index $D_{430} / D_{005}$ occur. Anisotropy has a clear vertical manifestation: surface phytoplankton shows, in general, a lower maturity than populations decper in the water. There seems to be a general exchange between parts of different maturity in a system. Usable potential energy flows from the less mature to the more mature part of the system, in the form of cells removed by sedimentation, diffusion or grazing by animals. On the other hand, the unispecific populations distributed over an anisotropic ecosystem, show local differences in demographic composition, in the form that a more juvenile composition, with a higher energy flow, is found in the places where the whole ecosystem is less mature, profiting in a eertain way of a surplus of usable energy. Such kind of relations are to bo observed in the distribution of zooplankton in and around of phytoplankton patches and, of course, in the presence of planktonic larvae of benth'c animals, which in the aduit state belong to a system much more mature than the plankton. These general considerations, that can be illustrated by many examples, may help to place the problems of patchiness in the frame of general ecology.

The anisotropy of an extense mixed population is compound there are gradients and patches of different scale or order, building a complex pattern. It seems interestiing to note that when differences in maturity are found repeatedly over small distances, they did not build a mosaic-like pattern, but rather a honeycomb pattern, the places of lower diversity being like the centers of cells, enclosed by a honeycomb of higher diversity, and not the converse.

It is contemplated that some of the problems posed can be better analized using an experimental approach, simulating natural conditions in a compound chemostat, made up by a number of culture vessels, interconnected in a three dimensional lattice, with controlled flow of medium. Some nutrients, or changed conditions, can be introduced or produced, respectively at a certain point of the systern, followed by diffusion of flow in one or more direetions. It remains only to wait for new steady state situations. 


\section{BIBIIOG R A F A}

BatNBridge, R. - 1957. The size, shape and density of marine phytoplankton con centrations. Biol. reviews, 32 : $91-115$.

Baidi, E.; A. Buzzati-Traverso, L. Cayalli \& L. Pirocchi. - 1945. Frammentamento di una popolazione specifica (Mixodiaptomus laciniatus Lillj.) in un grande lago in sottopopolazione geneticamente differenziate. Mem. Ist. Ital. Idrobiol., $2: 167-216$.

Baldi, E.; L. CavaliLi \& L. Pinocchi. -- 1947. Ulteriori ricerche sulla distribuzione spaziale del mesoplaneton pelagico in un grande lago oligotrofo. Mem. Ist. Ital. Idrobiol., $3: 123-149$.

Baldi, E. ; L. Cavatit, L. Prrocchi \& V. Tonolli. - 1949. L'isolamento delle popolazioni di Mixodiaptomus laciniatus Lillj. del lago Maggiore e i suoi nuovi problemi. Mem. Ist. Ital. Idrobiol., 5 :297-305.

Barnes, H. - 1953. Considerazioni statistiche sulla distribuzione spaziale di alcuni organismi planctonici raccolti su un lungo percorso nel Golfo della Clyde. Mom. Ist. Ital. Idrobiol., $7: 109-127$.

BARNEs, H., \& G. R. HAste. - 1957. A statistical examination of the distribution of some species of Dinoflagellates in the polluted inner Oslo fjord. Nytt Mag. Botan., 5 :118-123.

BARLETT, M. S. - 1960. Stochastic population models in Ecology and Epidemiology. Methuen \& Co., Londres, $90 \mathrm{pp}$.

BARY, B. M. - 1953. Sea-water discoloration by living organisms. New Zealand $J$. Sc. and Techn., B, 34(5):393-407.

- 1958. Temperature-salinity-planliton diagrams: Some application to oceanography and ecology. XVth Congress Zoology, III, p. 45. Londres.

Berzins, B. - 1958. Ein planktologisches Querprofil. Inst. Freshwater Res., Drottningholm, Rep. 39:5-22.

Bouraet, R., \& S. Broma. - 1960. Turbulent diffusion in the sen. Bull. Mar. Sci. Gulf and Caribboan, $10: 354-366$.

Bowden, K. F. - 1962. Turbulence. The Sea, I, 802-825. Interscience Publ.

BrAY, J. R. - 1958. Notes towards an ecologic theory. Ecology, 39:770-776.

Brockaw, C. J. - 1959. Random and orientated movements of bracken spermatozoids. J. Cell. Comp. Physiol., 54:95-101.

CASsIT, R. M. - 1957. The sampling problem, with particular reference to marine organisms. Proceod. Now Zealand Ecol. Soc., 4:37-39.

- 1958. Apparatus for investigating spatiäl distribution of plankton. New Zealand $J$. of Science, $1: 436-448$.

- 1959a. An experimental study of factors inducing aggregation in marine plankton. New Zealand J. Science, $2: 339-365$.

- 1959b. Micro-distribution of plankton. Now Zealand J. Scienco, $2: 398-409$.

- 1959c. Some correlations in replicate plankton samples. New Zealand. J. Science, $2: 473-484$.

- 1959d. Factors influencing the distribution pattern of plankton in the mixing zone between ocennic and harbour waters. New Zealand J. Sci., 3:26-50.

- 1962a. Microdistribution and other error components of C-14 primary production estomate. Limnol. and Oceanogr., $7: 121-130$.

- 1962b. Frequency distribution models in the ecology of plankton and other organisms. J. Anim. Eicol., $31: 65-92$.

Chew, F. - 1956. A tentative method for the prediction of the Florida red tide. Bull. Mar. Sci., Gulf Caribbean, 6:292-304.

Clark, Ph. J., \& F. C. Evans. - 1954. Distance to nearest neighbor as a measure of spatial relationships in populations. Ecology, $35: 445-453$.

Colmbrook, J. M. - 1960. Plankton and water movements in Windermere. J. Anim. Ecol., $29: 217-240$. 
Comita, G. W., \& J. J. Comita. - 1957. The internal distribution patterns of a calanoid copepod population, and description of a modified Clarke-Bumpus planlton sampler. Limnol. and Oceanogr., $2: 321-332$.

Cook, C. W. - 1960. The use of multiple regression and correlation in biological investigations. Ecology, $41: 556-560$.

Cooper, L. H. N. - 1960. Some theorems and procedures in shallow-water oceanography applied to the Celtic Sea. J. Mar. Biol. Assoc. U. K., 39:155-171, 173-208.

- 1961. Vertical and horizontal movements in the ocean. Ocoanography, Lectures at the Intern. Ocean. Congress, Nueva York, 1959. A.A.A.S. núm. 17, Washington, pp. 599-621.

Coutors, D. F. - 1959. Kinetics of bacterial growth: Relationship between population density and specific growth rate of continuous cultures. J. Gen. Microbiol., $21: 40-50$ (Coll. Repr. Scripps Inst. Ocennogr., núm. 1102).

Crisp, D. J. - 1962. Swarming of planlstonic organisms. Nature, 193 :597-598.

Currie, R. I. - 1962. Pigments in zooplankton faeces. Nature, $193: 956-957$.

Cushing, D. H. - 1953. Studies on plankton populations. J. Conseil, $19: 3-22$.

- 1962a. An alternative method of estimating the critical depth. J. Conseil, 27: 131-140.

- 1962b. Patchiness. Rap. Proc. Verb. C.I.E.M., $153: 152-164$.

Detla Croce, N., \& T. Sertorio. - 1959. Microdistribuzione dello zooplenliton. Boll. Mus. Ist. Biol. Univ. Genova, 28(175):1-28.

DoтY, M. S., \& M. OqunI. - 1958. Primary productivity patterns in enriched areas. Proceed. IXth Pacific Science Congress, 94-97.

Екомото, Y. - 1959. On conditions for the vernal blooming of phytoplankton. Bull. . Jap. Soc. Scientific Fish., $25: 172-182$.

Ewina, M. - 1950. Relation between band slicks at the surface and internal waves in the sea. Science, $111: 91-94$.

Frasento, R. - 1960. A preliminary survey of thermal microstructure in the Strait of Gibraltar. Deep-Sea Res., $7: 152-162$.

Frasetto, R. ; R. H. Backus \& E. Hays. - 1962. Sound-scattering layers and their relation to thermal structure in the Strait of Gibraltar. Deep-Sea Res., 9:69-71.

Gran, H. H., \& T. Braarud. - 1935. A quantitative study of the phytoplankton in the Bay of Fundy and the Gulf of Maine. J. Biol. Bd. Can., 1:279-467.

HARDY, A. C. - 1936. Observations on the uneven distribution of oceanic plankton. Discovory Reports, $11: 511$.

- 1952. Some problems of pelagic life. Essays in Marine Biology. Oliver \& Boyd, Edimburgo, pp. 101-121.

HASLE, G. R. - 1954. More on phototactic vertical migration in marine dinoflagellates. Nytt Mag. f. Bot., $2: 139-147$.

Haxo, F. T., \& K. A. Olendenning. - 1953. Photosynthesis and phototaxis in Ulva lactuca gametes. Biol. Bull., $105: 103-114$.

Heineich, A. K. - 1962. Peculiarities of the main plankton communities in the Pacific. Trude Instituta Okeanologii, 58 :114-134.

HeLA, I. - 1955. Ecological observations on a locally limited red tide bloom. Bull. Mar. Sci., Gulf Caribbean, 5:269-291.

Herrera, J., \& R. Margalef. - 1963. Hidrologia y fitoplancton de las aguas costeras desde Castellón al Ebro, de julio de 1960 a junio de 1961. Inv. Pesq. (En prensa.)

Hutohinson, G. E. - 1953. The concept of pattern in ecology. Proc. Acad. Nat. Sci. Philadelphia, $105: 1-12$.

- 1957. Concluding remarks. Cold Spring Harbor Symp. Quant. Biol., 22 :415-427.

- 1961. The paradox of the plankton. Amer. Nat., $95: 137-145$.

IonIYe, T., \& F. O. W. Olson. - 1960. Uther die neighbour diffusivity im Ocean. D. Hydrogr. Z., $13: 13-23$.

JanNasch, H. W. - 1963. Bestimmung mikrobieller Abbauraten in natürlichen Gewässern in Fliessgleichgewicht. XV Intern. Congress Limnology, Madison, 1962. (En prensa.)

JosePH, J. - 1960. On mixing processes in the sea. Disposal of radiactive wastes, $2: 82-91$. 
Joseph, J., \& H. Stendner. - 1958. Uber die horizontale diffusion im Meere. Deutsche Hydrogr. Z., 11(2):49-77.

KaYAMa, R. - 1961. New methods of quantitative representations on the structure of plant communities. Japan. J. Ecol., 11:4-10, 62-66, 93-97.

Kenshaw, K. A. - 1960. The detection of pattern and association. J. Ecol., 48 : $232-242$.

KEтCHUM, B. H. - 1954. Relation between circulation and planktonic populations in estuaries. Ecology, $35: 191-200$.

Kierstead, H., \& L. B. Slobonkin. - 1953. The size of water masses containing plankton blooms. J. Mar. Res., 12-141-147.

Krnsman, B. - 1957. Proper and improper use of statistics in geophysics. Tollus, $9: 408-418$.

Krey, T. - 1954. Beziehungen zwischen Phytoplankton, Temperatursprungschicht and Trübungssehirm in der Nordse im August 1952. Kieler Meoresf., 10:3-18.

Larvasto, T. - 1962. The adequacy of plankton sampling. Rap. Proc. Verb. C.I.E.M., $153: 66-73$.

Lafond, E. C. - 1962. Internal waves. The Sea, I:731-751. Interscience Publishers.

Lafond, E. C., \& C. Borneswara Rao. - 1954. Rotary currents. Current Science, 23,2 .

Landadtr, R. - 1961. Symposium on Self-regulation in living systems. Nature, $189: 800$.

LANGMUR, I. - 1938. Surface motion of water induced by wind. Sci., $87: 119-123$.

Manteured, B. P. - 1941. (Planeton y arenque en el mar de Barents.) Polianyi N. I. Institut Mors7kovo Rybnovo Khoziaistva $i$ Oleanografii, Trudy, $7: 125-218$.

Mardacige, R. - 1955. 'Temperatura, dimensiones y evolución. Publ. Inst: Biol. Apl., $19: 13-94$.

- 1956. Estructura y dinámica de la purga de mar en la Ría de Vigo. Inv. Pesq., $5: 113-134$.

- 1957a. Un modelo para el estudio de la distribución de organismos de gran dispersabilidad y área de reproducción muy localizade. Inv. Pesq., 7:117-125.

- 1957b. La teorf́a de la información en ecologla. Mem. Real Acad. Oiencias y Ar. tes de Barcolona, $32: 373-449$.

- 1958. Temporal succession and spatial heterogeneity in phytoplankton. Perspectives in marine biology. California Univ. Press, pp. 323-349.

- 1961a. Distribution du phytoplancton dans une échelle moyenno de dimensions et signification de ses pigments assimilateurs dans l'interprétation dynamique des configurations. Rapp. Proc. Verb. C.I.E.S.M., 16(2):139-140.

- 1961b. Correlations entre certains caractères synthétiques des populations de phytoplancton. Hydrobiologia, $18: 155-164$.

- 1961c. Hidrografía y fitoplancton de un área marina de la costa meridional de Puerto Rico. Inv. Pesq., 18:33-96.

- 1962. Modelos f́́sicos simplificados de poblaciones de organismos. Mem. Real Acad. Ciencias y Artes de Barcelona, 34:88-146.

- 1963a. Modelos simplificados del ambiente marino para el estudio de la sucesión y distribución del fitoplancton y del valor indicador de sus pigmentos. Inv. Pesq., $23: 11-52$.

- 1963b. Correspondence between the classical types of lakes and the structural and dynamic properties of their populations. $X V$ Intorn. Congross of Limnology, Madison, 1962. (En prensa.)

Marqaliti, R., \& J. Herrima. - 1963a. Hidrografia y fitoplancton de las costas de Castellón, de julio de 1959 a junio de 1960. Inv. Pesq., $22: 49-109$.

- 1963b. Hidrografía y fitoplaneton de las aguas costeras desde Castellón al Ebro, de julio de 1961 a junio de 1962. Inv. Pesq. (En prensa.)

Margalef, R., \& H. Ryther. - 1960. Pigment composition and productivity as related to succession in experimental populations of phytoplanlston. Biol. Bull., $119: 326-327$.

McAllister, C. D.; T. R. Parsons, K. Stephens \& J. D. Strickland, - 1961. Measurements of primary production in coastal sea water using a large-volume plastic sphere. Limnol. and Oceanogr., $6: 237-258$. 
Moon, F. W. ; Ch. L. Bretschnemen \& D. W. Hoop. - 1957. A method for measuring eddy diffusion in coastal embayments. Publ. Inst. Mar. Sci., 4:14-21 (Texas).

Moore, H. B. - 1952. Physical factors affecting the distribution of euphausids in the North Atlantic. Bull. Mar. Sci., Gulf Caribbean, 1:278-305.

Moser, H. - 1958. The dynamics of bacterial populations maintained in the chemostat. Carnegie Inst. Washington, publ. 614, $136 \mathrm{pp}$.

Munk, W. H., \& G. Rnex. - 1952. Absorption of nutrients by aquatic plants. J. Mar. Res., $11: 215-240$.

Nishizawa, S. - 1954. Preliminary study on the diffusive moviments of squid population. Bull. Fac. Fish. Holkkaido Univ., $5: 29-35$.

Noviok, A. - 1959. Experimentation with the chemostat. Recent progress in micro. biology, Almqvist \& Wiksell, Estocolmo, pp. 403-423.

Odரм, H. T. - 1960. Ecological potential and analogue circuits for the ecosystem. Amer. Scientist, $48: 1-8$.

OLson, F. C. W. - 1952. An empirical expression for horizontal turbulence. Florida State Univ. Studies, 7, 5 pp.

OLson, F. C. W., \& T. ICHIYe. - 1959. Horizontal diffusion. Science, $130: 1255$.

Ozmidov, R. V. - 1960. Horizontal turbulent diffusion of the pollutant patches in the sea. Trude Instituta Oleanologii, $37: 164-181$.

Patrien, B. - 1962. Species diversity in net phytoplankton of Raritan Bay. J. Mar. Res., $20: 57-75$.

Peapson, E. A., y colabs. - 1956. Mechanies of dispersion. State Water Pollution Control Board, publ. núm. 14, pp. 53-71. Sacramento, Calif.

Pielou, E. C. - 1959. The use of point-to-plant distances in the study of the pattern of plant populations. $J$. Ecol., $47: 607-613$.

- 1961. Segregation and symmetry in two speeies populations as studied by nearestneighbour relationships. $J$. Ecology, $49: 255-269$.

Pimentel, D. - 1961. Species diversity and insect population outbreaks. Ann. Ent. Soc. Amer., $54: 76-86$.

PlatT, J. R. - 1961. "Bioconvection patterns》 in cultures of free-swimming organisms. Science, $134: 1766-1767$.

Pomerov, L. R. ; H. H. Haskin \& R. A. Ragotzkis. - 1956. Observations on dinoflagellate blooms. Limnol. and Oceanogr., 1:54-60.

Pow wiL, E. O.--1958. Criteria for the growth of contaminants and mutants in continuous culture. J. Gen. Microbiol., $18: 259-268$.

Pringli, J. W. S. - 1951. On the perallel between learning and evolution. Behaviour, $3: 174-215$.

Pritohard, D. W., \& P. E. Kent. - 1956. A method for determining mean longitudinal velocities in a coastal plain estuary. J. Mar. Res., 15:81-91.

RAGOTZITE, R. A., \& R. A. BRYson. - 1955. Hydrography of the Duplin River, Sapelo Island, Georgia. Bull. Mar. Sci. Gulf d Caribbean, $5: 297-314$.

RagotzkIE, R. A., \& L. R. Pomeroy. - 1957. Life history of a dinoflagellate bloom. Limnol. and Oceanogr., $2: 62-69$.

Riohardson, L. F. - 1952. Transforms for the eddy-diffusion of clusters. Proc. Royal Soc. London, A, 110:709-727.

RILEY, G. A. - 1942. The relationship of vertical turbulence and spring diatom flowerings. J. Mar. Res., $5: 67-87$.

- 1951. Parameters of turbulence in the sea. J. Mar. Res., 10:247-265.

Ridey, G. A.; H. Srommer \& D. F. Bumpus. - 1949. Quantitative ecology of the plankton of the Western North Atlantic. Bull. Bingham Oc. Coll., 12(3):1-169.

Rosengourth, M. Ch. - 1962. (Islas de agua dulce en el Mar Negro.) Priroda, 8 : $119-120$.

Rórschi, H. ; B. Wauthy \& M. Legand. - 1961. Orsom III. Resultats de la croisière «Epi», 2. Inst. Français Océanie, Centre Océanogr., Rapp. Sc. $n^{0} 23,113$ pp.

Rovbatut, A. - 1946. Obsérvations sur la répartition du plancton. Bull. Inst. Océanographie, Monaco, nủm. $902,4 \mathrm{pp}$.

RYther, J. H., \& E. M. HoLnurt. - 1960. On winter mixing and the vertical distribution of phytoplanlston. Limnol. and Oceanogr., $5: 337-338$.

SaIN'-GuILY, B, - 1962. Le problème d'Ekman pour un océan formé par deux couches d'eau superposées. Deep Sea Res., 9:199-208. 
Saraent, M. C., \& T. J. Walkerr. - 1948. Diatom populations associated with eddies off Southern California in 1941. J. Mar. Res., $7: 490-505$.

SLobodkin, L. B. - 1953. A possible initial condition for red tides on the coast of Florida. J. Mar. Res., $12: 148-155$.

- 1958. Meta-models in theoretical ecology. Ecology, $39: 550-551$.

- 1961. Preliminary ideas for a predictive theory of ecology. Amer. Natur., 95 : 147-153.

Smayda, Th. J. - 1958. Biogeographical studies of marine phytoplankton. Oikos, $9: 158-191$.

SVERDRUP, H. U. - 1953. On conditions for the vernal blooming of phytoplankton. J. Conseil, $18: 287-295$.

Tsudita, T. - 1955. Studies on the explosive multiplication of plankton with special reference to the «red water». Bull. Seikai Reg. Fish. Res. Labor., Nagasakif $6: 11-60$.

Udsitalo, S. - 1961. On the diffasivity of turbulent flow. Geophysica, $7: 191-193$.

Voluenwitder, R. A. - 1956. Beitrag zur Theorie der Schwarmbildung. Mem. Ist. Ita7. Idrobiol., $9: 265-272$.

Wilitims, W. T., \& J. M. Lambert. - 1961. Nodal analysis of associated populations. Nature, $191: 202$.

Williamson, M. H. - 1961. A method for studying the relation of plankton variations to hydrography. Bull. Mar. Ecol., $5: 224-229$.

Winge, O. - 1923. The Sargasso Sea, its boundaries and vegetation. Rep. Dan. Ocean. Exp. 1908-1910 Medit. adj. seas, 3(2):1-34.

Winsor, C. P., \& G. Is. Clarke. - 1940. A statistical study of variation in the catch of planliton nets. J. Mar. Res., $3: 1-34$.

Whitraken, R. H. - 1961. Estimation of net primary production of forest and shrub communities. Ecology, $42: 177-180$. Woopcocr, A. H. - 1941. Surface cooling and streaming in shallow fresh and, salt
waters. J. Mar. Res., $4: 153-160$.

- 1950. Subsurface pelagic Sargassum. J. Mar. Res., 9:77-92.

Wooncock, A. H., \& J. Wrman. - 1947. Convective motion in the air over the sea. Ann. N. Y. Acad. Sci., 48:749-776.

YeNTsGH, Ch. S., \& C. A. Reichert. - 1962. The interrelationship between watersoluble yellow substances and chloroplastic pigments in marine algae. Botanica Marina, $3: 65-74$.

Yentsch, Ch. S., \& J. H. Ryther. - 1959. Absortion curves of acetone extracts of deep water particulate matter. Deep Sea Res., $6: 72-74$. 